\title{
Altered Dermal Fibroblasts in Systemic Sclerosis Display Podoplanin and CD90
}

Banafsheh Nazari, * Lisa M. Rice, * Giuseppina Stifano, * Alexander M.S. Barron, ${ }^{* \dagger}$ Yu Mei Wang, ${ }^{*}$ Tess Korndorf, ${ }^{*}$ Jungeun Lee, Jag Bhawan, ${ }^{\ddagger}$ Robert Lafyatis, ${ }^{\star \S}$ and Jeffrey L. Browning ${ }^{* \dagger}$

From the Section of Rheumatology* and the Departments of Microbiology ${ }^{\dagger}$ and Dermatology, ${ }^{\ddagger}$ Boston University School of Medicine, Boston, Massachusetts; and the Division of Rheumatology and Clinical Immunology, ${ }^{\S}$ University of Pittsburgh Medical Center, Pittsburgh, Pennsylvania

Accepted for publication

June 3, 2016.

Address correspondence to Jeffrey L. Browning, Ph.D. Boston University School of Medicine, 72 E Concord St, Room E-501, Boston, MA 02118. E-mail: browninj@bu. edu.

\begin{abstract}
Tissue injury triggers the activation and differentiation of multiple cell types to minimize damage and initiate repair processes. In systemic sclerosis, these repair processes appear to run unchecked, leading to aberrant remodeling and fibrosis of the skin and multiple internal organs, yet the fundamental pathological defect remains unknown. We describe herein a transition wherein the abundant $\mathrm{CD}_{3} 4^{+}$dermal fibroblasts present in healthy human skin disappear in the skin of systemic sclerosis patients, and CD34 ${ }^{-}$, podoplanin ${ }^{+}$, and $\mathrm{CD}^{+} 0^{+}$fibroblasts appear. This transition is limited to the upper dermis in several inflammatory skin diseases, yet in systemic sclerosis, it can occur in all regions of the dermis. In vitro, primary dermal fibroblasts readily express podoplanin in response to the inflammatory stimuli tumor necrosis factor and IL-1 $\beta$. Furthermore, we show that on acute skin injury in both human and murine settings, this transition occurs quickly, consistent with a response to inflammatory signaling. Transitioned fibroblasts partially resemble the cells that form the reticular networks in organized lymphoid tissues, potentially linking two areas of fibroblast research. These results allow for the visualization and quantification of a basic stage of fibroblast differentiation in inflammatory and fibrotic diseases in the skin. (Am J Pathol 2016, 186: 2650-2664; http://dx.doi.org/10.1016/j.ajpath.2016.06.020)
\end{abstract}

Systemic sclerosis ( $\mathrm{SSc}$ ) is a connective tissue disease characterized by immune dysregulation, vasculopathy, and fibrosis in multiple organ systems. ${ }^{1}$ Chronic tissue injury as in cases of unresolved infection, inflammatory disease, or cancer can often lead to fibrosis. ${ }^{2}$ In SSc, these remodeling processes appear to proceed unchecked over years, yet the fundamental driver of the pathology remains unknown. Considerable attention has focused on transforming growth factor (TGF)$\beta$-triggered conversion of mesenchymal lineage cells to $\alpha$-smooth muscle actin (SMA) - positive myofibroblasts as the central event in fibrosis. ${ }^{3,4}$ Recently, elegant fate-mapping strategies have been used in the mouse to define the origin of these myofibroblasts and potentially the fibrotic process. ${ }^{5-7}$ Indeed, a separate fibroblast lineage with enhanced fibrogenic potential was revealed using these methods. ${ }^{8}$ Despite these advances, the etiology of SSc remains poorly understood and patients lack effective treatments. We were intrigued by the rapid progress in the understanding of fibroblast specialization in the context of lymphoid organs. In this setting, reticular stromal networks are not mere matrix scaffolds, but play active roles in orchestrating lymphocyte interactions and in the formation and wrapping of specialized collagen fibrils, called conduits. $^{9-11}$ The responsive or reactive lymph node represents an unusual case of reversible, physiological tissue remodeling in what is effectively an inflammatory microenvironment. ${ }^{12-14}$ With chronic lymph node reactivity, such as in HIV or Yersinia infection, forms of Hodgkin lymphoma and IgG4-related disease, fibrosis can ensue. ${ }^{15-18}$ Therefore, we questioned whether similar processes were in play in the skin of SSc patients.

There is considerable heterogeneity in fibroblast populations and phenotypic information on the various

\footnotetext{
Supported by NIH Clinical \& Translational Science Institute grant UL1TR000157; National Institute of Arthritis and Musculoskeletal and Skin Diseases grants 5P30AR061271, 1P50AR060780, and 2R01AR051089 (R.L.); and NIH grant 5T32A1007309-27 (A.M.S.B.).

B.N. and L.M.R. contributed equally to this work.

Disclosures: BS1 antibody was provided by Biogen.
} 
differentiation states remains imprecise. ${ }^{19,20}$ The skin is richly populated throughout the dermis by CD34-expressing fibroblasts with long dendritic processes. ${ }^{21}$ Electron microscopy reveals the presence of an intricate network of fibroblasts within the dermis, perhaps even interlinked by intercellular stromal connections. ${ }^{21}$ Dermal fibroblast nomenclature is not standardized and includes such terms as telocytes, fibrocytes, and dendrocytes. Herein, we will use the newly proposed term $\mathrm{CD} 34^{+}$stromal fibroblastic cell or CD $34^{+}$SFC. $^{22}$ Curiously, it has been known for $>20$ years that this expression of dermal stromal CD34 is lost in SSc. ${ }^{23-29}$ This change is not limited to SSc skin, as it is seen in the scarring after skin lesion excision, dialysis-induced peritoneal fibrosis, and keloids. ${ }^{30-32}$ A fundamental question is whether these cells simply degenerate and disappear or are they activated and have changed their phenotype. In this work, we show that $\mathrm{CD} 34^{+}$SFC convert or are replaced by podoplanin $^{+}$(Pdpn) and CD90 ${ }^{+}$fibroblasts in SSc and this process can occur quickly in response to normal skin injury.

\section{Materials and Methods}

\section{Patient Specimens}

The Boston University Medical Center Institutional Review Board approved procedures and analyses, and informed consent was obtained from all patients and healthy subjects. Skin biopsy specimens were provided by SScores, the NIH Scleroderma Core Center at Boston University Rheumatology. The skin biopsy specimens for histology were taken from the dorsal mid-forearm region of SSc patients, including 48 diffuse cutaneous SSc (dcSSc), 2 undifferentiated, 24 limited cutaneous SSc, and 11 healthy controls. The characteristics of these subjects are outlined in Supplemental Table S1. Additional biopsy specimens $(n)$ from affected skin were obtained from cutaneous (discoid) lupus erythematosus (eight, aged 26 to 71 years, female 100\%), psoriasis (six, aged 43 to 77 years, female $33 \%$ ), subacute (five, aged 45 to 74 years, female 60\%), and chronic (twelve, aged 19 to 73 years, female $42 \%$ ) spongiotic dermatitis and lesional tissue from dermatofibroma (eight, aged 43 to 60 years, female $75 \%$ ), dermatofibrosarcoma protuberans (six, aged 49 to 68 years, female 50\%), atypical fibroxanthomas (six, aged 47 to 95 years, female 20\%), and neurofibroma (eight, aged 41 to 78 years, female $75 \%$ ) patients. The human skin scars were obtained after re-excision of the margins from previously excised skin lesions after varying intervals. Scar tissues were examined from five different patients with recent excisions (early scar, 7 to 8 days) and eight patients with longer intervals (late scars, 28 to 31 days). The Boston University Medical Center Dermatopathology Section provided tonsil and skin samples.

Microarray data from skin biopsy specimens were available for $35 \mathrm{dcSSc}$ and seven healthy controls, as previously described. ${ }^{33}$ Two separate data sets were obtained using the same U133A 2.0 chip (Affymetrix, Santa Clara, CA). ${ }^{33,34}$
These data were normalized for batch differences using the ComBat algorithm (SVA 3.18 package; Bioconductor http://www.bioconductor.org/packages/release/BiocViews. html\#_Software). ${ }^{35}$ Determination of genes whose expression correlated with either the Pdpn/CD34, CD90/CD34 RNA ratios or modified Rodnan skin score (MRSS) was performed using $\mathrm{R}$ (3.2.1) on the combined data from 35 $\mathrm{dcSSc}$ and seven controls. Paired biopsy specimens were obtained from the same forearm region from a subset of patients $(30 \mathrm{dcSSc})$ for both histological and RNA analyses. In addition, histological analysis was conducted on multiple (two to three) biopsy specimens obtained over a 1-year spread from three of the dcSSc patients and, similarly, transcriptome data were available from two to three biopsy specimens from four of the dcSSc patients.

\section{Immunohistochemistry}

A double-staining protocol was used on paraffin-embedded slides after dewaxing and heat antigen retrieval in Tris/EDTA pH 9.0 for 20 minutes, except in the case of Figure 1, no heat retrieval was performed. Blocking was achieved using 3\% $\mathrm{H}_{2} \mathrm{O}_{2}$ followed by BloxAll (Vector Labs, Burlingame, CA) or $2 \%$ horse serum. Appropriate Vector ImmPress Polymers (mouse, rat, and rabbit) were used to detect primary antibodies, followed by development with either Vector AMEC [red, horseradish peroxidase (HRP)], HighDef Blue (Enzo, HRP), or Vector Blue (alkaline phosphatase). Vector ABC was used for detection of biotinylated primary antibodies. For immunofluorescence, the same procedures were used, only the detection of HRP-ImmPress polymers was performed sequentially using Alexa-Tyramide reagents (Thermo Fisher Scientific, Waltham, MA): Alexa Fluor 488 and Alexa Fluor 594 tyramide. Biotinylated anti- $\alpha$-SMA was detected using Vector-ABC-HRP, a Biotin-XX-tyramide step followed by Streptavidin-Alexa Fluor 405 or Vector-ABC-HRP was followed with CF405S Tyramide (Biotium, Fremont, CA). Each labeling step was followed by $\mathrm{HRP}$ quenching with $3 \% \mathrm{H}_{2} \mathrm{O}_{2}$ before the next stain. Typically, primary antibodies were retitrated for use with tyramide amplification. Triple-stained immunofluorescence protocols for transitional cells included sequential layers of mouse anti-CD34, rabbit anti-CD90, or mouse anti-Pdpn, rabbit anti-CD34 followed by biotinylated mouse anti-CD31. Costaining for procollagen used mouse anti-procollagen I, rabbit anti-CD90 (or rabbit anti-Pdpn). Immunofluorescence slides were imaged using an Olympus FlouView FV10i confocal microscope (Olympus, Waltham, MA). Antibodies were as follows: mouse anti-human CD31 (JC70A; Dako, Carpinteria, CA), biotinylated mouse antihuman CD31 monoclonal antibody (mAb; C31.3+JC/70A; Novus Biologics, Littleton, CO), mouse anti-human CD34 mAb (QBEnd10; Dako), rabbit anti-human or mouse CD34 mAb (EP373Y; Abcam, Cambridge, MA), rabbit anti-human CD90 mAb (EPR3132; Abcam), mouse anti-human Pdpn mAb (D2-40, Dako), rabbit anti-human Pdpn mAb (128994, Abcam), biotin-hamster anti-mouse Pdpn mAb 


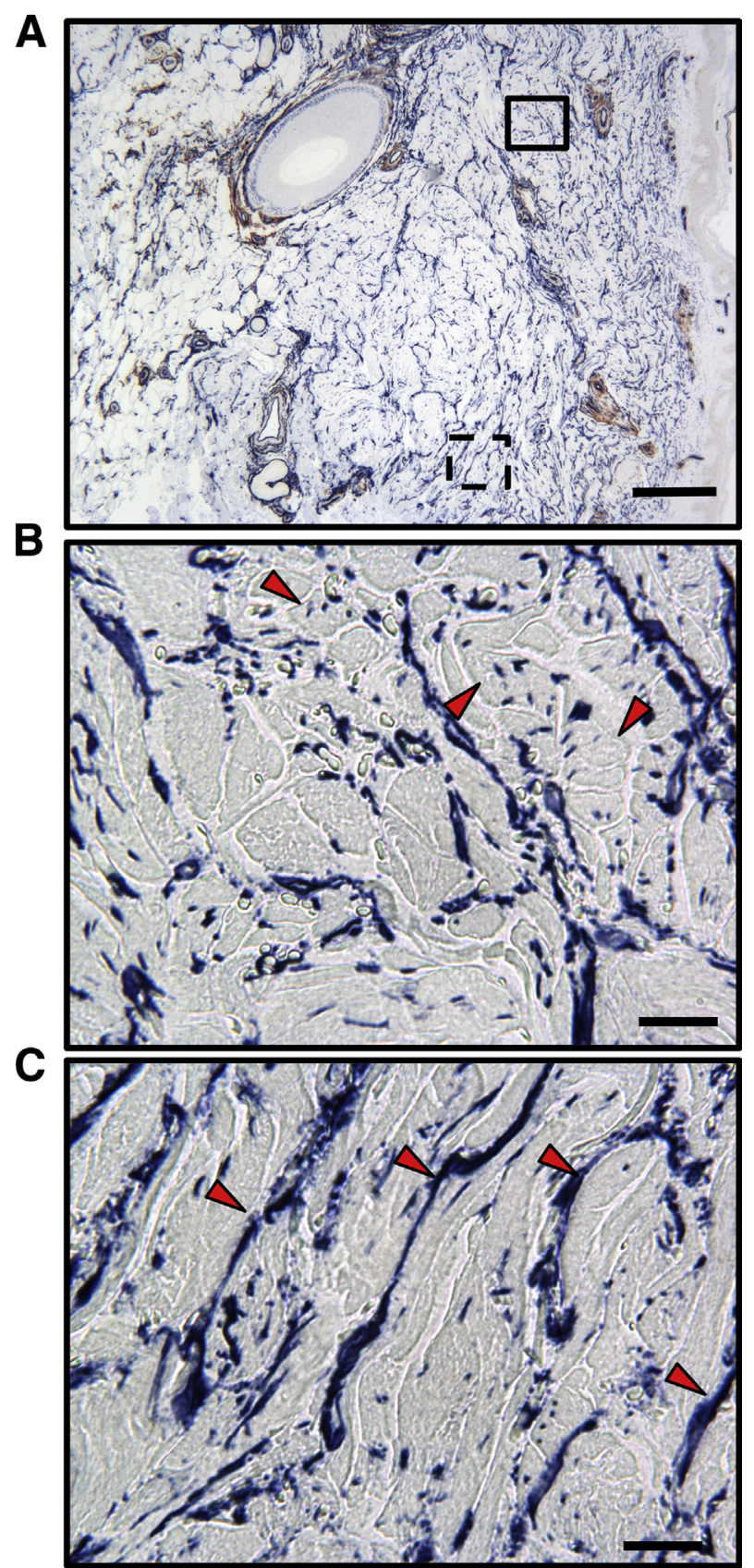

Figure $1 \mathrm{CD}^{+} 4^{+}$stromal fibroblast cells are oriented parallel to the collagen fibers in normal skin forming an intricate network. A: Low magnification image of normal skin stained for CD34 (blue) and CD90 (brown). CD34 stains the stromal fibroblasts as well as endothelial cells, whereas CD90 marks predominantly perivascular adventitial cells and structures within the hair follicle. Two dermal regions are magnified (solid boxed area is shown in B and the dashed boxed area is shown in C) and highlighted by phase contrast to show many fine $\mathrm{CD}_{3} 4^{+}$processes captured in cross section (arrowheads in B) when fibers were similarly transected. Long extended $\mathrm{CD} 34^{+}$ fibroblast-like cells are observed running parallel to the fibers (arrowheads in C). Epidermis is to the right. Scale bars: $200 \mu \mathrm{m}$ (A); $25 \mu \mathrm{m}$ (B and C).

(8.1.1; eBioscience, San Diego, CA), rabbit anti-nerve growth factor receptor $\mathrm{mAb}$ (EP1039Y, Abcam), biotin and nonbiotinylated mouse anti- $\alpha$-SMA mAb (1A4/asm-1, Dako and Thermo Scientific), and mouse anti-procollagen I mAb (clone SP1.D8, Developmental Studies Hybridoma Bank, Iowa City, IA).

\section{Mouse Skin Wounds}

For skin wound experiments, C57.B6 mice were anesthetized and the back was shaved. A mid-dorsal 1-cm incision cut was made through the skin with a scalpel and the wound was sealed with Liquid Bandaid. Mice were euthanized, and the cut skin was taken on days 0,1 , and 4 after the initial incision. Skin sections were formalin-fixed and paraffin-embedded for histology. The Boston University Institutional Animal Care and Use Committee approved the mouse procedures.

\section{Dermal Fibroblast Cultures}

Primary human dermal fibroblasts from skin biopsy specimens from healthy donors or SSc patients as well as human foreskin fibroblasts were derived as previously described and used before passage 6 to $7 .{ }^{36}$ Various agents were added in fresh media with $10 \%$ fetal bovine serum with $20 \mathrm{ng} / \mathrm{mL}$ tumor necrosis factor (TNF), $20 \mathrm{ng} / \mathrm{mL} \mathrm{IL-1} \beta, 20 \mathrm{ng} / \mathrm{mL}$ IL-6 (R\&D Systems, Minneapolis, MN), $100 \mathrm{ng} / \mathrm{mL}$ LT $\beta$ receptor (LT $\beta R$ ) agonist BS1, $10 \mathrm{ng} / \mathrm{mL}$ platelet-derived growth factor (PDGF) AA and PDGFBB (Preprotech, Rocky Hill, $\mathrm{NJ}$ ), $500 \mathrm{U} / \mathrm{mL}$ interferon- $\alpha 4$ (PBL Interferon Source, Piscataway, NJ) or $5 \mathrm{ng} / \mathrm{mL}$ human TGF- $\beta$ (R\&D Systems). BS1 is a bispecific antibody recognizing two non-crossblocking epitopes on the receptor, thereby enabling extensive oligomerization of the receptor on the surface. As such, it is an effective mimic of the normal cell surface ligand and its properties have been described. ${ }^{37}$ BS1 was a gift from Biogen (Cambridge, MA). RNA was isolated from these cultures after 24 hours and subjected to either quantitative PCR using TaqMan primers or a custom human gene specific 78 gene Nanostring array effectively as described. ${ }^{38}$ For immunohistological analysis, cells were grown on Nunc glass chamber slides, stimulated as above, fixed with formaldehyde, and permeabilized with $100 \%$ methanol. Cells were stained sequentially with anti-Pdpn (D2-40), Alexa 594-labeled goat anti-mouse IgG, quenching with mouse IgG, biotinylated anti- $\alpha$-SMA (1A4, Thermo Fisher), and streptavidin-Alexa 488 , followed by counterstaining with DAPI and imaging on the Olympus confocal.

\section{Results}

Loss of $\mathrm{CD} 4^{+}$Dermal Fibroblasts Is Accompanied by the Appearance of $\mathrm{CD}_{3} 4^{-} /$Podoplanin $^{+} / \mathrm{CD}^{+} 0^{+}$ Reticular Cells in SSc

In normal skin, reticular cells expressing CD34 form a dense network within the dermis. Figure 1 shows at relatively high resolution, long fibroblast-like cells running parallel to the fibers; however, when a fiber was transected, the CD34 

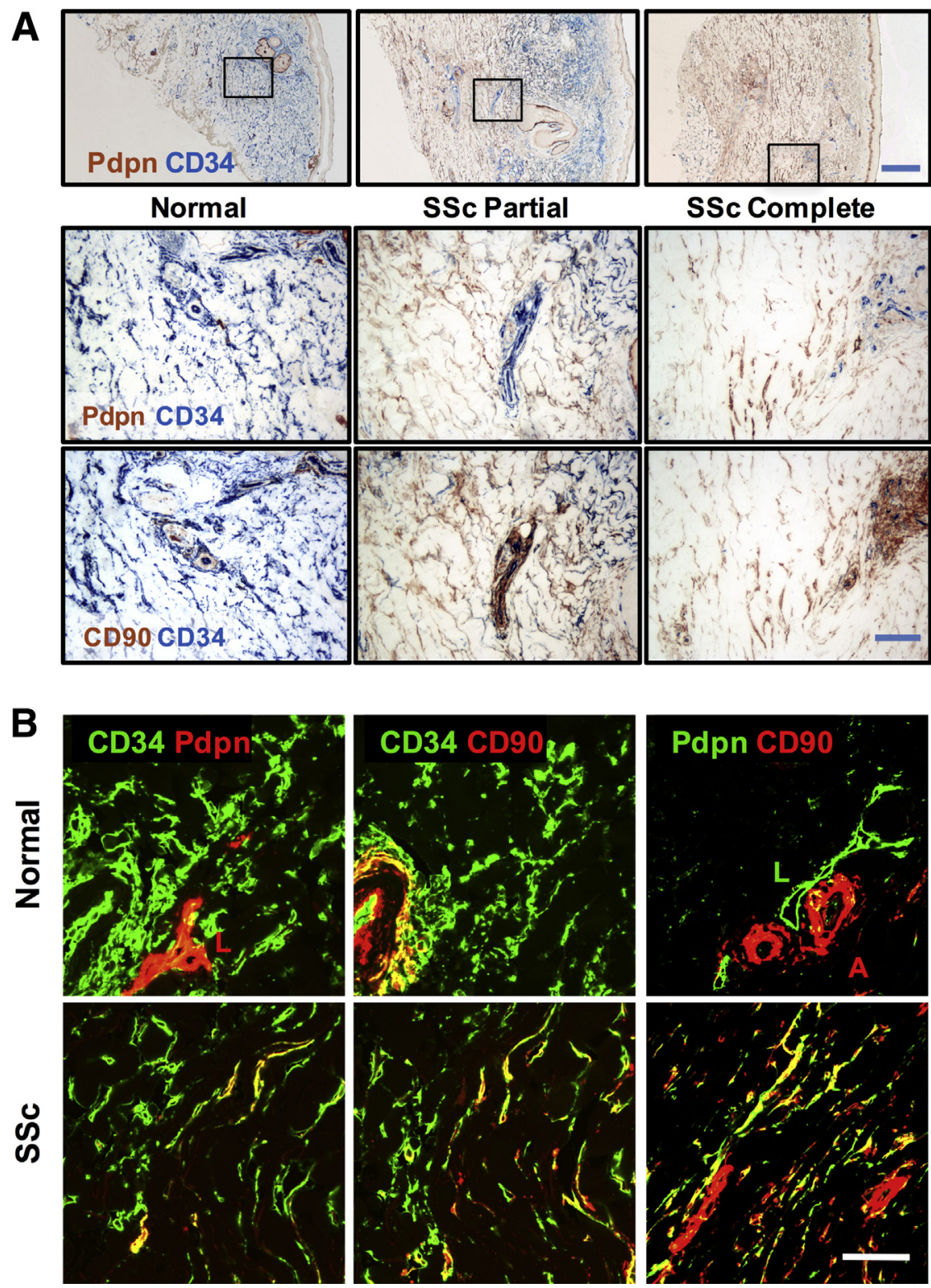

Figure 2 A transition of $\mathrm{CD} 34^{+}$dermal fibroblasts to a Pdpn and $\mathrm{CD}^{+} 0^{+}$state occurs in the dermis of SSc patients. A: Examples are shown of normal skin and skin from SSc patients with either a partial or complete transition (top panels). Boxed area is magnified in bottom panels. Pdpn expression is seen in transitioned fibroblasts as well as lymphatic vessels, keratinocytes, hair follicles, and sebaceous glands. CD90 expression is observed in vascular adventitia and transitioned fibroblasts. B: Immunofluorescence imaging showing a subset of transitioning cells in SSc skin displaying both CD34 and Pdpn and/or CD90. Pdpn and CD90 costaining was performed on a different section compared to the CD34 panels. Scale bars: $0.5 \mathrm{~mm}$ (A, top panels); $100 \mu \mathrm{m}$ (A, bottom panels); $50 \mu \mathrm{m}$ (B). A, adventitia; L, lymphatic. staining was punctate in appearance. This staining pattern reveals a dense and intricate web of fibroblastic processes consistent with the electron microscopy-based description of a network of CD34 ${ }^{+}$SFC with thin, long processes. ${ }^{21}$ In dcSSc skin, cells positive for Pdpn and CD90 (alias Thy1) replaced to varying extents the dense network of $\mathrm{CD}^{+}{ }^{+}$ SFC in normal healthy skin (Figure 2A). Fibroblastic Pdpn staining was weaker than the normally intense lymphatic staining yet was readily visible using the standard D2-40 $\mathrm{mAb}$. Loss of lymphatic staining occurs in dcSSc skin and, although not documented herein, we also noted the loss of lymphatic capillaries in the upper dermis. ${ }^{39-42}$ Some biopsy specimens displayed a partial conversion that was observed in either the papillary or reticular dermis, and an example of such a partial transition in the reticular dermis is seen in Figure 2A. Other patient biopsy specimens completely lacked $\mathrm{CD} 4^{+} \mathrm{SFC}$ and transitioned cells dominated both dermal layers (ie, a pan-dermal transition). Thus, there was considerable patient-to-patient heterogeneity with the range of patterns varying between conversion in only one layer (only Pdpn or CD90 or both), a pan-dermal transitioned state and a presumably more final state with few cells of any phenotype. When examined, biopsy specimens obtained 6 to 12 months apart were similar in histological status (not shown). Biopsy specimens from patients with limited cutaneous SSc $(n=24)$ from clinically unaffected forearms largely resembled normal skin in terms of this transition.

Pdpn is a common marker for lymphatic endothelium, but it also defines the specialized reticular stroma in lymphoid organs in mice and human. ${ }^{43-46}$ In addition, Pdpn is expressed in normal sebaceous glands, hair follicle roots, activated keratinocytes, some carcinoma cells, and non-transformed cancerassociated fibroblasts. ${ }^{43,47,48}$ Enhanced Pdpn expression in 
keratinocytes was frequently observed in SSc, indicating some level of epidermal perturbation. CD90 is normally found on neuronal cells, mesenchymal stem cells, pericytes, perivascular adventitial fibroblasts, and a relatively rare subset of human $\mathrm{T}$ lymphocytes. ${ }^{49-51}$ Using immunofluorescence microscopy and a SSc biopsy with a partial transition, we found a subset of dermal cells that were positive for CD34 along with Pdpn and/ or CD90, and these cells were not $\mathrm{CD} 31^{+}$endothelial cells (Figure 2B and Supplemental Figure S1). One interpretation of this staining is that these are $\mathrm{CD} 34^{+} \mathrm{SFC}$ caught in the process of conversion. Many stromal cells displayed both Pdpn and CD90 (Figure 2B). However, fibroblasts positive for just Pdpn or CD90 were readily observed, consistent with phenotypic heterogeneity. $\mathrm{CD} 34^{+} \mathrm{SFCs}$, as well as the transitioned cells, did not stain for nerve growth factor receptor (CD271), although some fibroblast-like cells in the perivascular adventitial layer were positive (data not shown).

To determine whether the Pdpn or $\mathrm{CD} 90^{+}$cells in SSc skin were actually fibroblasts, we costained sections with antiprocollagen I. Procollagen was found in a roughly Golgilike perinuclear localization and where cell bodies were seen, $\mathrm{CD} 34^{+} \mathrm{SFC}, \mathrm{Pdpn}^{+}$, and $\mathrm{CD} 90^{+}$cells displayed procollagen staining (Supplemental Figure S2). Given the convoluted network-like nature of these staining patterns, not all Pdpn or $\mathrm{CD} 90^{+}$processes could be exactly linked to a particular cell body. In addition, we costained the cells with vimentin (Supplemental Figure S3). CD34 ${ }^{+}$SFC-like cells in fibrous tumors have a vimentin cytoskeleton as typical of fibroblasts. ${ }^{22}$ Likewise, the $\mathrm{Pdpn}^{+}$or $\mathrm{CD} 0^{+}$cells also costained with vimentin, indicating that all three cell types have a cytoskeleton consistent with a fibroblastic lineage. Murine CD90 ${ }^{+}$fibroblasts were previously shown to be vimentin positive. ${ }^{52}$ These observations indicate that the Pdpn and $\mathrm{CD} 90^{+}$stromal cells appearing in SSc skin are fibroblasts.

\section{Relationship Between Transitioned Fibroblasts and Myofibroblasts}

As this transition appeared to represent a new differentiation event or an activation state of normal dermal fibroblasts, we questioned whether these cells are simply the classic $\alpha-\mathrm{SMA}^{+}$ myofibroblasts. $\alpha$-SMA ${ }^{+}$myofibroblasts are observed in many SSc skin biopsy specimens in regions with thickened parallel collagen bundles deep in the dermis. ${ }^{53,54}$ More important, $\mathrm{CD} 90^{+}$or $\mathrm{Pdpn}^{+}$cells were readily observed in sections lacking $\alpha$-SMA ${ }^{+}$myofibroblasts, indicating that this differentiation pathway to the $\mathrm{Pdpn} / \mathrm{CD} 0^{+}$state can occur independently from the conversion to myofibroblast (Figure 3 and Supplemental Figure S4). In SSc biopsy specimens with pronounced fibrosis, conventional $\alpha$-SMA ${ }^{+}$myofibroblasts were readily observed and $\alpha$-SMA colocalized with either or both $\mathrm{CD} 90$ and $\mathrm{Pdpn}^{+}$cells (Figure 3). Myofibroblasts expressing either CD90 or Pdpn have been observed in several settings, although CD90 interactions are reported to block fibrosis. ${ }^{52,55,56}$ These $\alpha$-SMA ${ }^{+}$costaining patterns were often complex, yet consistent with a narrow focal plane through contorted, twisting cells (Supplemental Figure S5). Myofibroblasts run parallel to the fibers and like with $\mathrm{CD} 34^{+} \mathrm{SFC}$, the staining patterns are additionally dictated by the plane-ofsection of the fiber bundles. Separate $\alpha-\mathrm{SMA}^{+}$and Pdpn/ $\mathrm{CD} 90^{+}$cells could be entwined; however, the similar patterns of vimentin costaining with CD34, Pdpn, and CD90 favor the simple interpretation. Similar complex patterns of CD90 and $\alpha$-SMA costaining were seen previously in myofibroblasts in mouse sclerotic skin. ${ }^{52} \alpha$-SMA ${ }^{+}$myofibroblasts without any Pdpn or CD90 display appeared to be rare, but this plane-ofsection complexity prevented an absolute determination. Therefore, the transition defines phenotypic changes that may occur either in parallel with or as an intermediate in the progression to a myofibroblast.

\section{Transition Occurs in Both Mouse and Human Skin Wounds}

We postulated that this phenotypic conversion is a basic form of fibroblast differentiation in response to injury. Human skin undergoing repair and scar formation after an excisional biopsy exhibited the transition with more Pdpn or CD90 being observed in both early ( 7 to 8 days) and late (28 to 31 days) phase scar samples (Figure $4 \mathrm{~A}$ ). Mouse skin also has $\mathrm{CD} 34^{+} \mathrm{SFC}$ in the dermis and, similar to the human setting, introduction of an incisional wound led to the appearance of $\mathrm{Pdpn}^{+}$cells (Figure 4B). By day 1 postincision, cells displaying both $\mathrm{CD} 34$ and Pdpn were observed (Figure 4C) and, therefore, this rapid and extensive conversion in response to injury is consistent with fibroblast differentiation and less likely to result from replacement by newly immigrating cells or rapid expansion of local progenitor cells. Thus, the transition can be a fast response to skin injury in both human and rodent skin.

\section{Human Dermal Fibroblasts Express Podoplanin in Response to Inflammatory Stimuli}

To determine whether dermal fibroblasts have the capacity to display Pdpn or CD90, we examined various signaling systems for the ability to induce these markers in cultured primary dermal fibroblasts from normal adults. Exposure of cells to TNF or IL-1 $\beta$ led to a robust induction of Pdpn RNA, but did not appreciably affect CD90 or CD34 RNA (Figure 5A). Dermal fibroblasts derived from SSc patients and normal foreskin fibroblasts behaved similarly. Interferon- $\alpha$, IL-6, PDGFAA, PDGFBB, TGF- $\beta$, and retinoic acid did not increase Pdpn or CD90 expression in contrast to the ability of TGF- $\beta$ and STAT3 activation to induce Pdpn in cultured epithelial cells. ${ }^{48}$ Cultured fibroblasts derived from murine lymphoid tissue up-regulated Pdpn after a combination of canonical and alternative NF- $\kappa \mathrm{B}$ activation, and we paralleled this format with the human dermal fibroblasts. ${ }^{57}$ Alternate NF- $\kappa \mathrm{B}$ signaling was triggered with an agonist antibody to the LT $\beta$ R and weakly induced Pdpn RNA expression, yet the combination with TNF was most effective. 

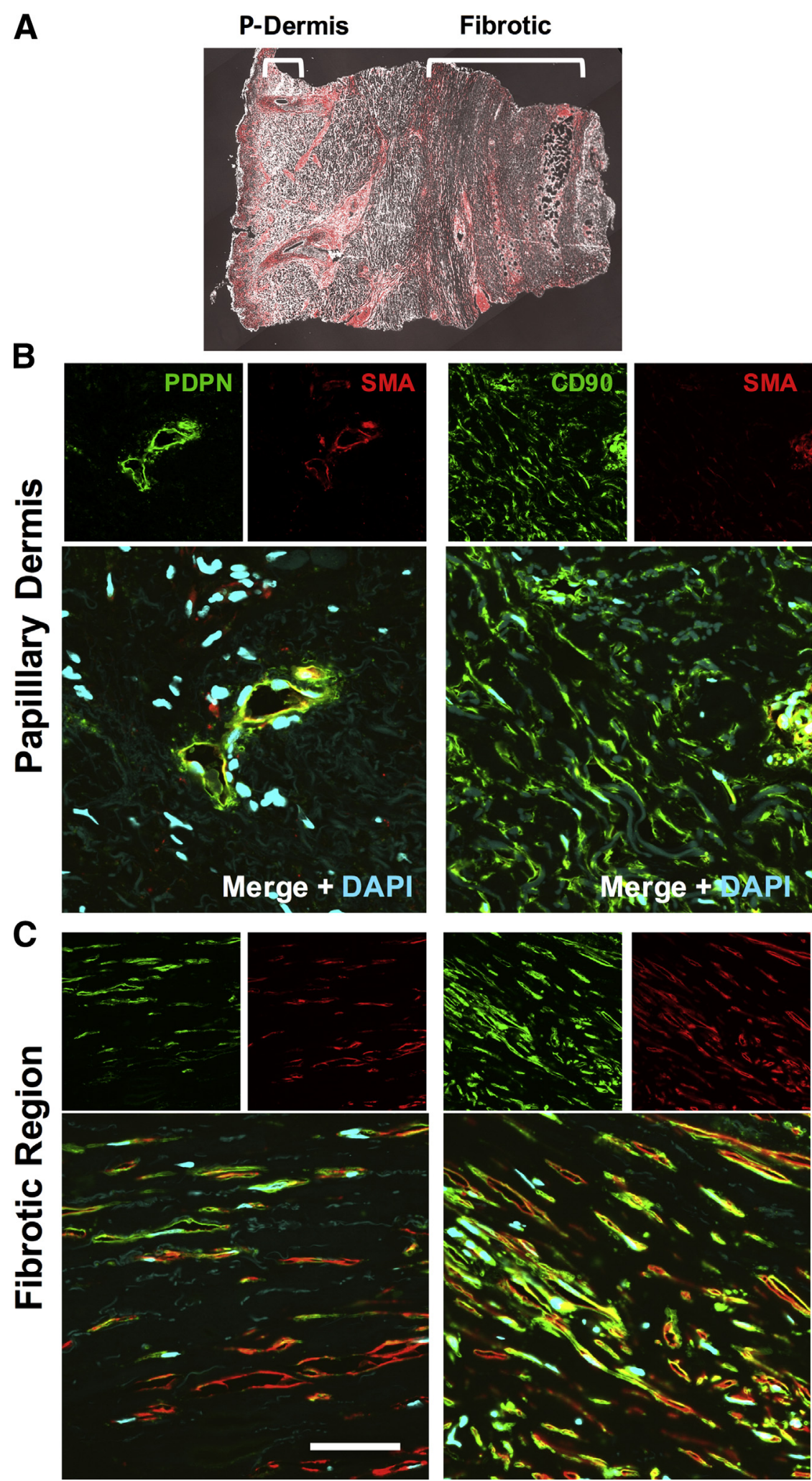

\section{Fibrotic}
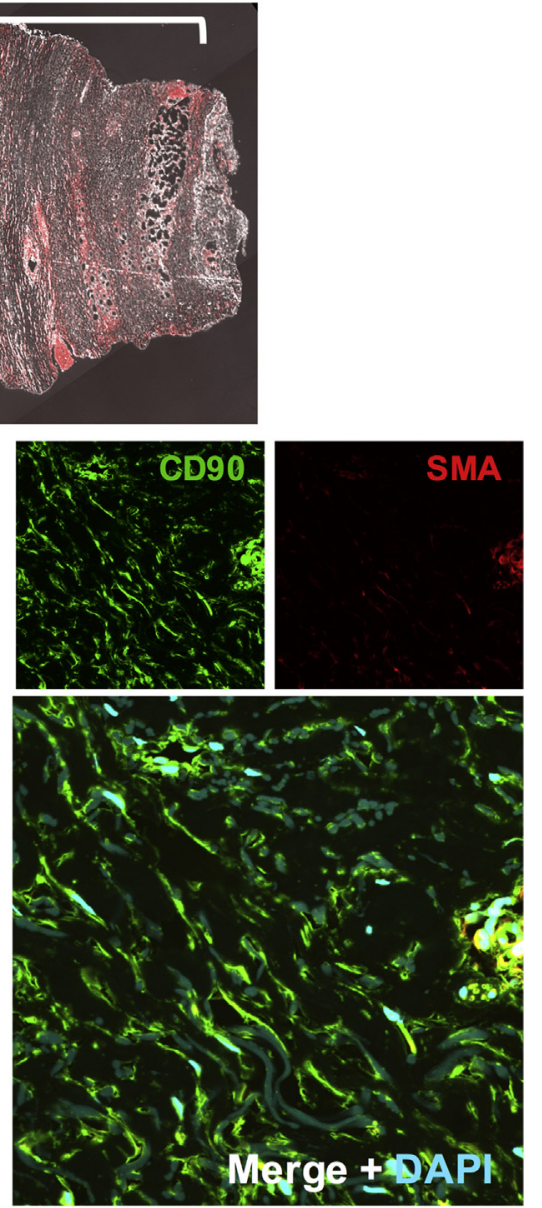

Figure 3 Immunofluorescence analysis of the relationship between $\operatorname{CD} 34, \alpha$-smooth muscle actin $(\alpha-S M A)$, Pdpn, and CD90 expression in SSc. Sections from dcSSc skin from a patient with extensive deep fibrosis were stained with either Pdpn/ $\alpha$-SMA or CD90/ $\alpha$-SMA and counterstained with DAPI. A: Entire biopsy specimen is shown with just the $\alpha$-SMA (red) and phase contrast channels. B: Example of the papillary dermis showing few $\mathrm{Pdpn}^{+}$transitioned fibroblasts, yet there is extensive CD90 expression. Within this region, there was a $\mathrm{Pdpn}^{+} \alpha-\mathrm{SMA}^{+}$lymphatic (collecting duct), but no $\alpha-\mathrm{SMA}^{+}$myofibroblasts. C: In the fibrotic region, there is a range of Pdpn expression on $\alpha$-SMA ${ }^{+}$myofibroblasts; however, most myofibroblasts express CD90. Scale bar $=50 \mu \mathrm{m}$ (B and C, large panels).
Immunohistological analysis of stimulated fibroblasts showed that stimuli that increased Pdpn RNA also increased protein expression (Figure 5B). Although the TNF or IL-1 $\beta$ induction of Pdpn RNA was maximal at day 1, robust protein expression required 3 to 5 days, as was the case with the cultured lymphoid reticular cells and in vivo in reactive lymph nodes. ${ }^{12,57} \mathrm{CD} 34$ RNA levels were low in these cultured primary fibroblasts and therefore we do not believe there were any major changes in CD34 expression with the various stimuli (Figure 4A). The typical relative RNA abundance of these genes based on 


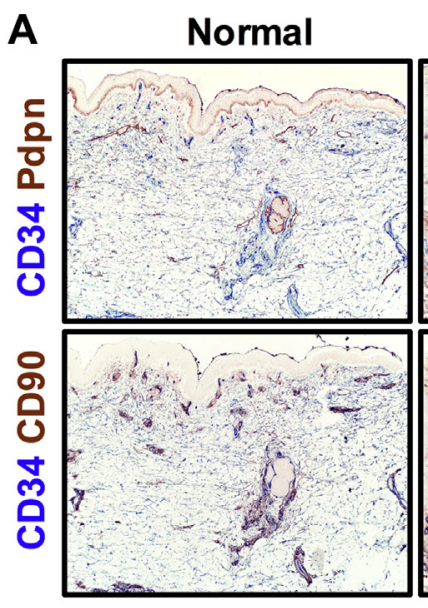

B

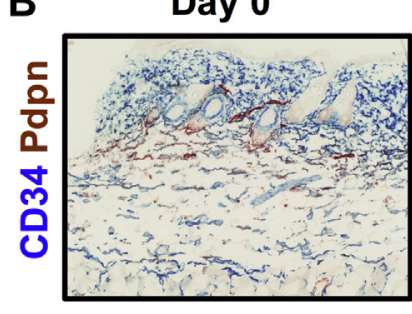

C

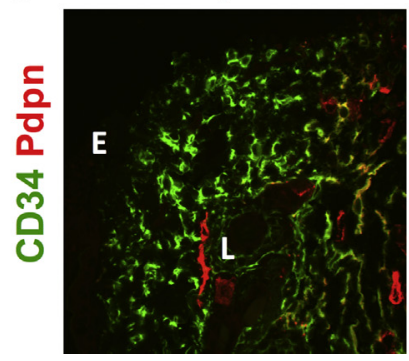

Early Scar

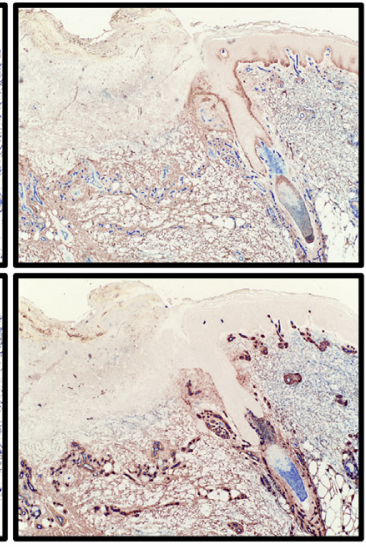

Day 1

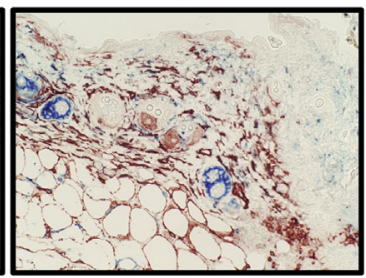

Day 1

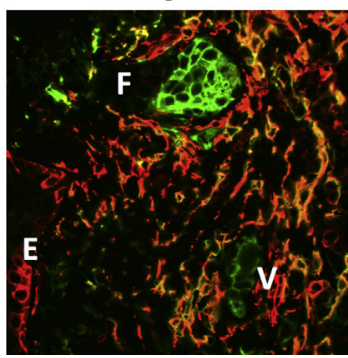

Late Scar

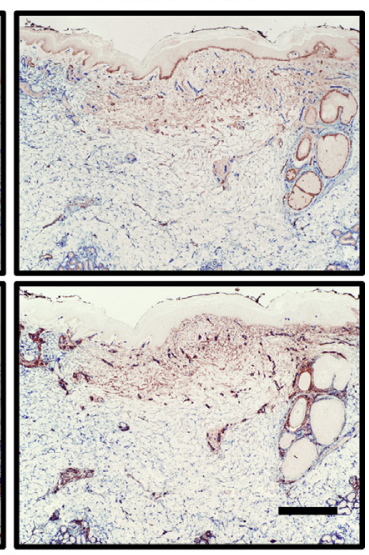

Day 4

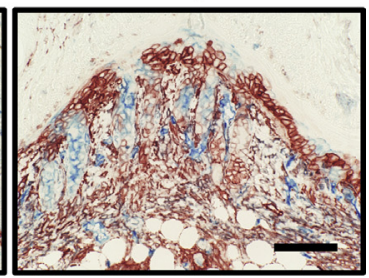

Day 4

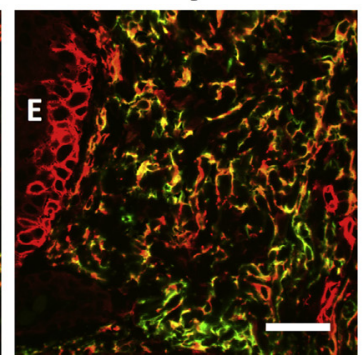

Figure 4 Analysis of the fibroblast conversion in human and mouse skin wounds. A: Transitioning fibroblasts in re-excised human skin 8 days (early scar) and 29 days (late scar) after the initial biopsy. Normal in this case was a region of skin with unperturbed architecture considerably distal to the initial lesion. B: Similar analysis of mouse skin after a skin incisional wound showing the rapid appearance of $\mathrm{Pdpn}^{+}$transitioned cells. At day 0 , the network of $\mathrm{CD}_{3} 4^{+} \mathrm{SFC}-$ like fibroblasts can be seen in the dermis in the layer containing the hair follicles. C: Immunofluorescence analysis of CD34 and Pdpn showing co-expression in samples from B. Scale bars: $200 \mu \mathrm{m}$ (A); $100 \mu \mathrm{m}$ (B); 40 $\mu \mathrm{m}(\mathbf{C})$. E, epidermis; $F$, hair follicle; L, lymphatic; $\mathrm{V}$, blood vessel.

quantitative PCR was $18 \mathrm{~S}, 1$; CD34, $1 \times 10^{-6}$; Pdpn, $3 \times$ $10^{-5} ; \mathrm{CD} 90,1 \times 10^{-3}$. Thus, the cultured cells have low CD34 coupled with high-level CD90 expression. We examined whether TGF- $\beta$ signaling could induce Pdpn expression in parallel with myofibroblast formation. Pdpn RNA was not induced by TGF- $\beta$ treatment, yet expression of Serpine1, a known TGF- $\beta$-induced gene, was elevated (Figure 5C). Likewise, TGF- $\beta$-treated dermal fibroblasts did not increase Pdpn expression; however, organized $\alpha$-SMA ${ }^{+}$fibers were readily seen (Figure 5D). In a culture of dermal fibroblasts derived from a dcSSc patient, some $\alpha-\mathrm{SMA}^{+}$as well as Pdpn ${ }^{+}$ cells were observed without stimulation, as could be expected with their increased presence in SSc skin. These data show that human dermal fibroblasts can express Pdpn in an inflammatory environment, and this event is independent of the TGF$\beta$-induced myofibroblast transition.

\section{A More Spatially Limited Transition Occurs in Other Inflammatory Skin Diseases}

The transition was observed in the inflamed skin from patients with psoriasis, subacute and chronic spongiotic dermatitis, and cutaneous (discoid) lupus erythematous. In general, the transition was localized to the inflamed papillary dermal layer (Figure 6). In this survey, SSc was unique, as the transition in some patients could be found in the deep dermis or throughout the entire dermis. Our observations also include phenotypic changes in the fibroblasts in the vascular adventitial layer. Notably in SSc, the perivascular adventitial fibroblasts exhibited increased CD90, but not Pdpn, staining. Consistent with vascular disruption, this compartment was often expanded in SSc skin.

\section{Relationship Between the Transition and Markers of SSc Disease}

We compared the histological features of the fibroblast transition in SSc skin with the levels of CD34, Pdpn, and CD90 RNA using adjacent paired skin biopsy specimens from $30 \mathrm{SSc}$ patients. Given the loss of CD34 and gain of CD90 or Pdpn protein expression in SSc, we speculated that the ratio of Pdpn/CD34 or CD90/CD34 RNA may track with the histological transition. The extent of histological 
A
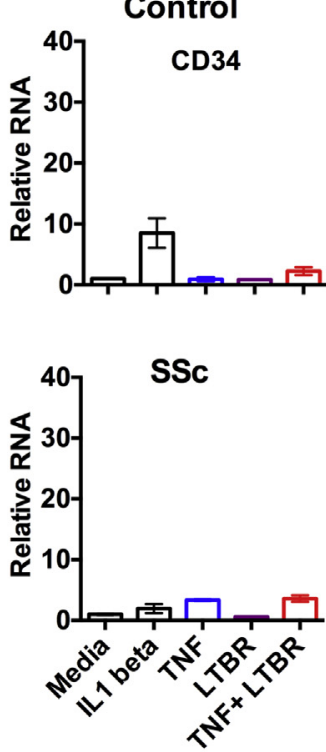

B
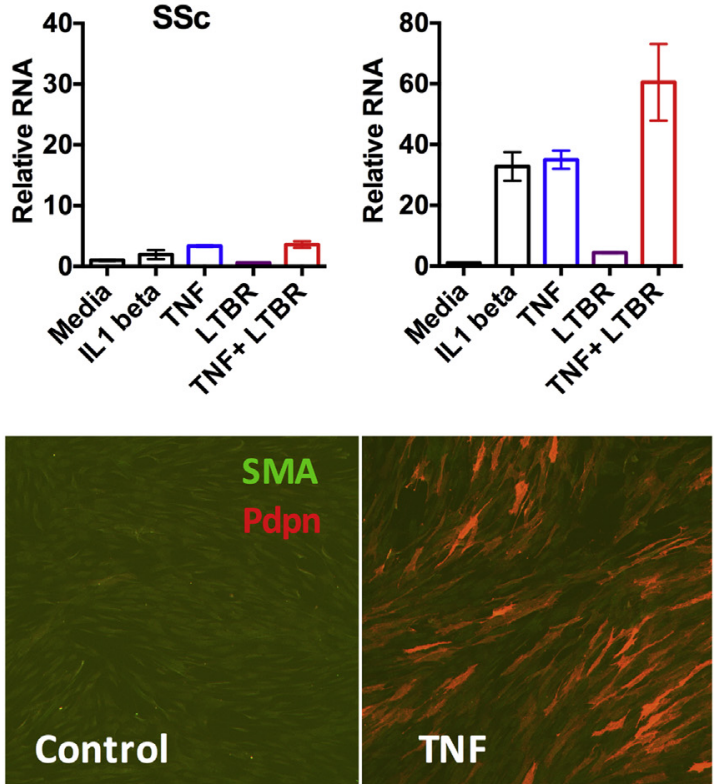

C

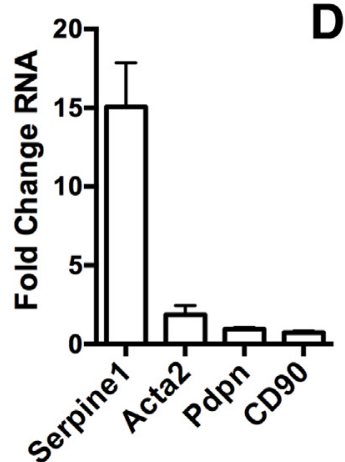

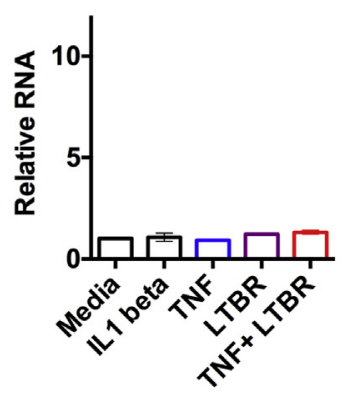
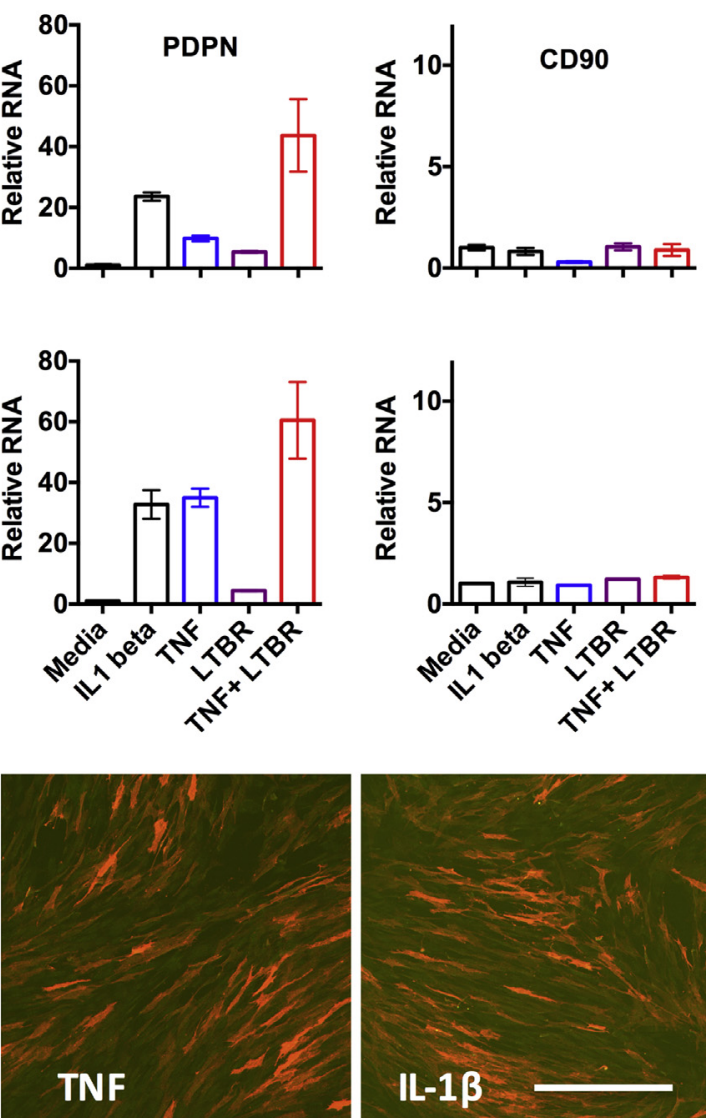

Figure 5 Inflammatory stimuli induce Pdpn expression in cultured dermal fibroblasts. A: RNA levels of Pdpn, but not CD34 or CD90, are induced by inflammatory stimuli in primary adult human dermal fibroblasts. Representative experiments with cells from normal and SSc skin after culturing for 24 hours with tumor necrosis factor (TNF), IL$1 \beta$, BS1 anti-LT $\beta$ receptor agonist antibody, and the combination of TNF and BS1. Bars show the range of values from biological replicates. B: Immunofluorescence imaging analysis of the induction of Pdpn protein and $\alpha$-smooth muscle actin ( $\alpha$-SMA) expression in normal human dermal fibroblasts after 5 days of exposure to media alone, TNF, or IL-1 $\beta$. C: Induction of $\alpha$-SMA but not Pdpn expression after culturing for 5 days in transforming growth factor (TGF)- $\beta$. Cells from this $\mathrm{dcSS} c$ patient when cultured in control media retain a low percentage of $\alpha$-SMA ${ }^{+}$and $\mathrm{Pdpn}^{+}$cells and in this regard, this field is illustrative, but overrepresents the density of $\alpha$-SMA ${ }^{+}$cells. These $\alpha-\mathrm{SMA}^{+}$or $\mathrm{Pdpn}^{+}$cells are not normally seen in unstimulated cultured normal dermal fibroblasts. D: RNA analysis of TGF- $\beta$-treated cells (24-hour exposure, normal dermal fibroblasts) showing robust induction of TGF- $\beta$-induced Serpine1, a slight increase in $\alpha$-SMA, yet no increase in Pdpn or CD90 RNA. Scale bar $=100 \mu \mathrm{m}$ (B and D). conversion was graded as low (no or little), medium (partial), or high (extensive to complete transition). Histological conversion correlated with higher ratios of Pdpn/CD34 and CD90/CD34 RNA (Figure 7A). The CD90/CD34 RNA ratio correlated well with the degree of dermal thickening, as defined by the standard MRSS, a subjective scoring system for skin thickness (Figure 7B). The Pdpn/CD34 ratio increased with increasing disease; however, the correlation was not strong in patients with lower MRSS values. If Pdpn expression is decreasing because of loss of lymphatics coupled with a gain of Pdpn expression with the transition, then the net effect of disease severity on the Pdpn/CD34 ratio could be more variable. In contrast, CD90 expression increased in all settings (ie, in both transitioning fibroblasts and in perivascular adventitial cells).
The lack of precise correlation between the two ratios, the heterogeneity in the immunohistochemical patterns, and the apparently differing requirements for RNA induction in cultured fibroblasts suggested that Pdpn and CD90 may be reporting on different aspects of the biology. Historically, elements of inflammation, proliferation, and fibrosis have been defined by transcriptional profiling of SSc skin. ${ }^{58,59}$ To explore this question, we identified those genes from the total skin biopsy microarray analysis that correlated with the Pdpn/CD34 and CD90/CD34 RNA ratios as well as MRSS values. Using a cutoff of $\mathrm{q}<0.05$, we found 49 genes associated with the Pdpn/CD34 ratio, 530 with CD90/CD34, and 437 with MRSS (Figure 4 and Supplemental Table S2). Figure 7C shows a heat map for association with the Pdpn/ $\mathrm{CD} 34$ ratio, indicating there is a molecular signature of this 

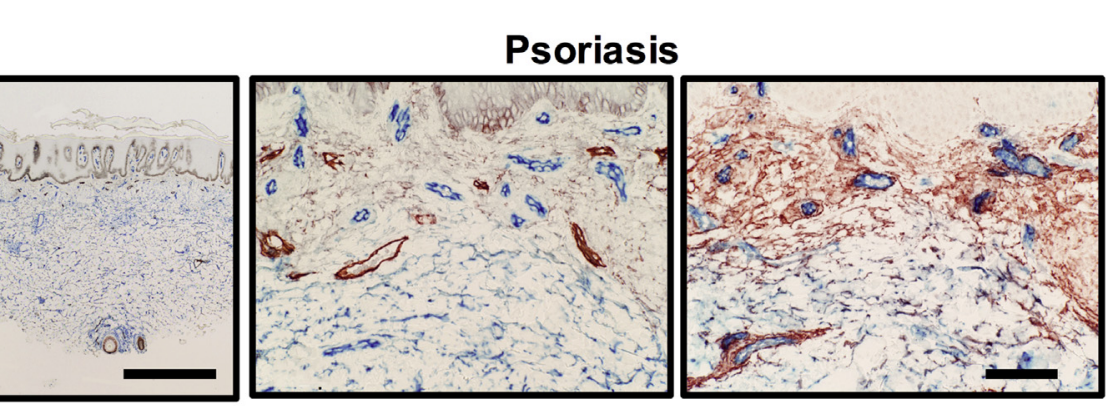

Subacute Spongiotic Dermatitis
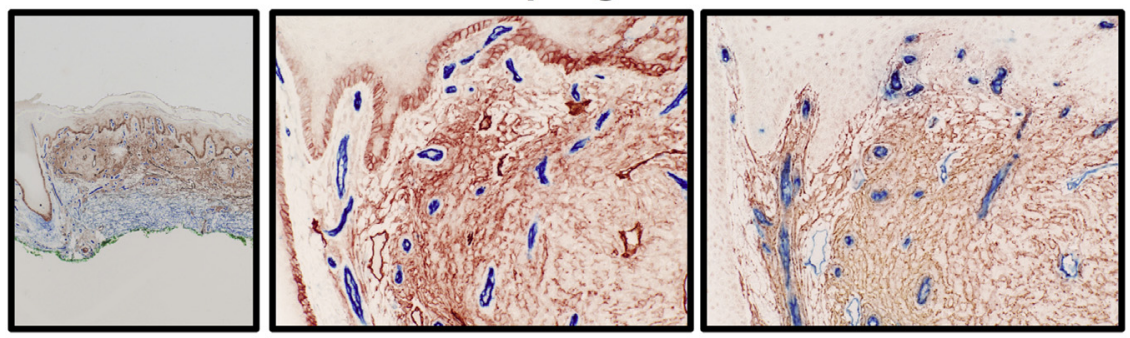

Cutaneous Lupus

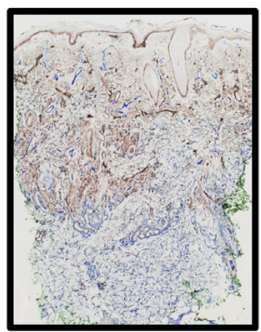

Pdpn CD34

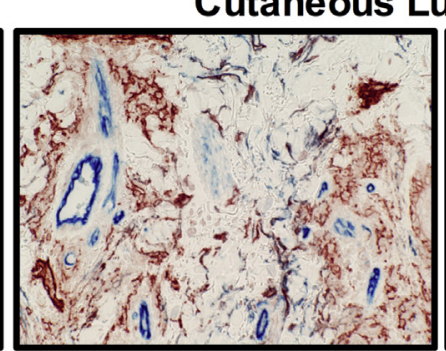

Pdpn CD34

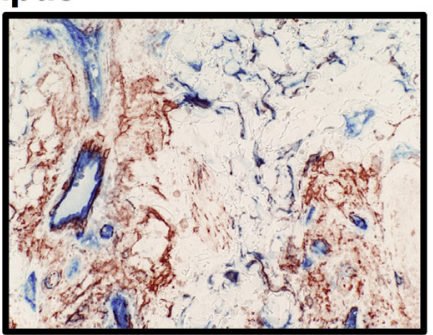

CD90 CD34
Figure 6 The fibroblast transition in inflammatory human skin diseases. Dual staining showing the CD34 to Pdpn/CD90 transition in various diseases (low and high magnification of the Pdpn/CD34 staining). Transitioned fibroblasts are found primarily in the upper dermis with relatively normal $\mathrm{CD}_{3} 4^{+}$fibroblastic cells being seen in the deeper regions of the dermis in each disease. Scale bars: $1 \mathrm{~mm}$ (left column); $100 \mu \mathrm{m}$ (middle and right columns). transition. Further heat maps for CD90/CD34 and MRSS can be seen in Supplemental Figures S6 and S7. Given the good correlation of the CD90/CD34 ratio with MRSS, it was not surprising that THBS1, a previously defined marker of fibrosis, correlated well with both MRSS and CD90/CD34 ratio, but not with Pdpn/CD34. In general, the spectrum of genes associating with the $\mathrm{Pdpn} / \mathrm{CD} 34$ ratio was rather distinct from those in the MRSS and CD90/CD34 data sets. In all three analyses, macrophage genes (eg, AIF1, CD163, or MRC1) did not reach the cutoff. This analysis is consistent with the concept that the Pdpn/CD34 transition reports potentially on a novel aspect of the pathology.

\section{Lymphoid Reticular Cells Are Phenotypically Similar to} Transitioned Dermal Fibroblasts

In light of our original premise that the lymphoid stromal networks may provide novel insight into fibroblast differentiation in nonlymphoid tissues, we compared the expression patterns of CD34, Pdpn, and CD90 in the human tonsil. Some fibroblastic reticular cells in the T-cell regions of the human tonsil express both Pdpn and CD90, yet lack CD34, thus resembling the phenotype of the dermal transitioned fibroblasts (Figure 8 and Supplemental Table S3). A subset of Pdpn/CD90 double-positive reticular cells resembling murine marginal reticular cells was described in the human lymph node. ${ }^{60}$ Notably, we observed in the submucosal region of the tonsil, $\mathrm{CD} 34^{+}$SFC-like cells resembling those in the skin. In addition, CD34/Pdpn double-positive stromal cells could be seen bridging into the lymphoid regions (Supplemental Figure S8). The second major reticular network in lymphoid tissues scaffolds the B-cell follicles and germinal center reactions and is composed of follicular dendritic cells, which are also of fibroblastic lineage. These cells are CD34 negative and Pdpn bright, but lacked CD90 expression. Thus, it is clear that there is heterogeneity in terms of CD90 and Pdpn expression in these specialized lymphoid reticula. From these observations, we conclude that lymphoid reticular networks share some phenotypic components with transitioned dermal fibroblasts.

\section{Transition in Dermally Derived Tumors}

Mesenchyme-derived skin tumors could stem from transformative events occurring at different points along their differentiation paths. We examined four such tumors, dermatofibroma (DF), dermatofibrosarcoma protuberans (DFSP), atypical fibroxanthoma (AFX), and neurofibroma for CD34, Pdpn, and CD90 expression (Supplemental Table S4 and Supplemental Figure S9). Previously, it was known 
A
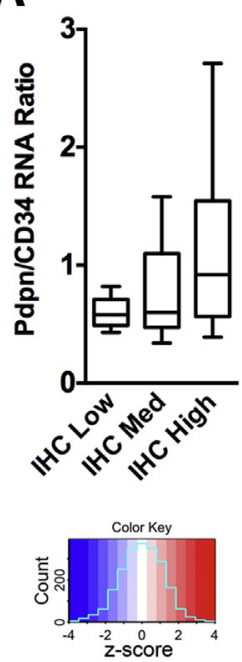

B

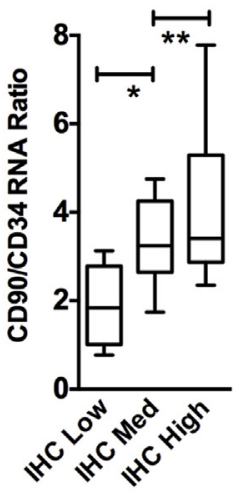

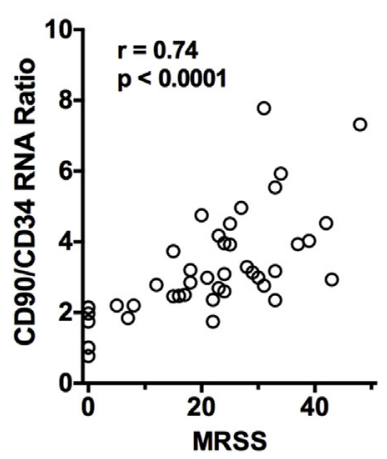

\section{PDPN/CD34}

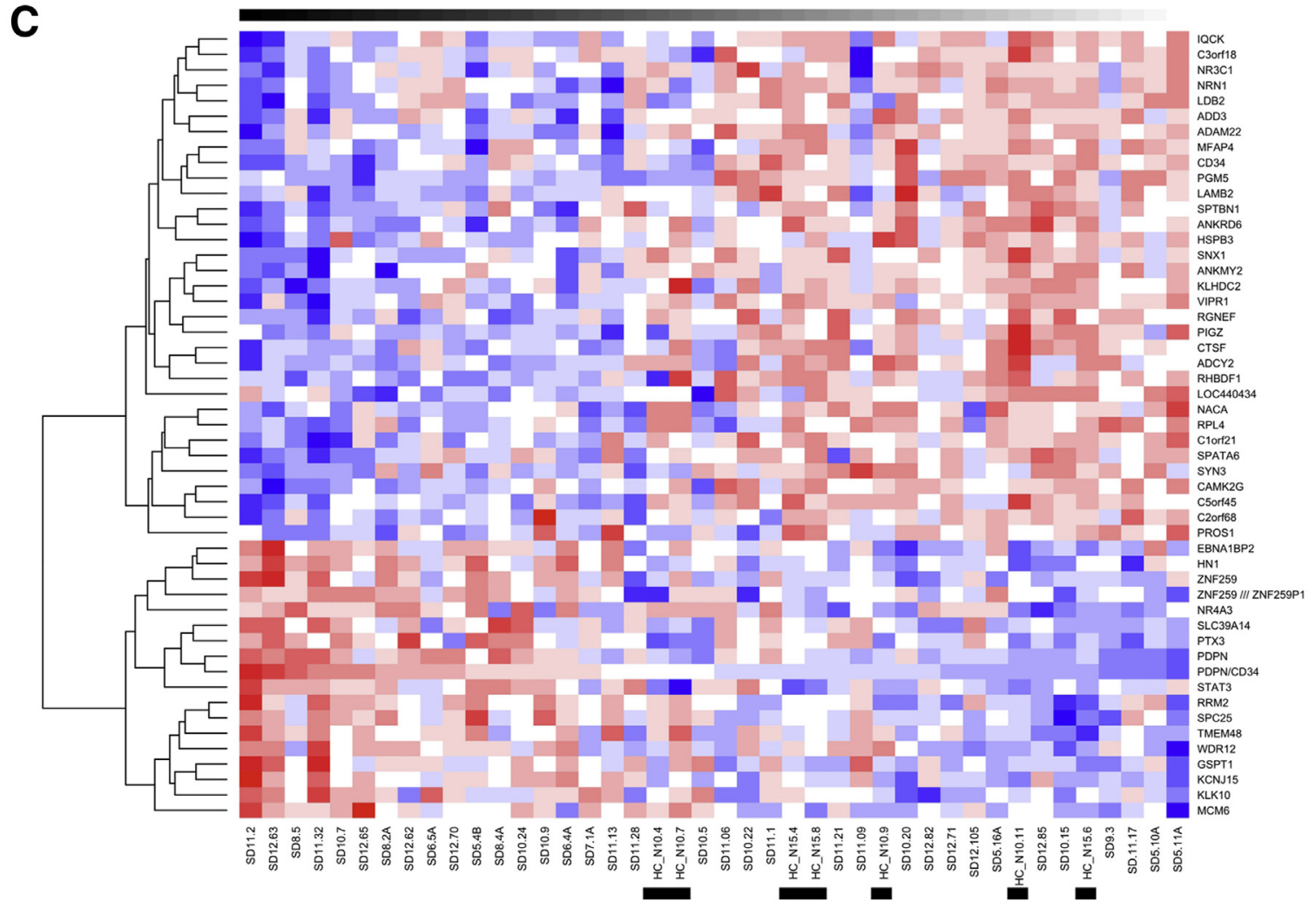

Figure 7 Relationship between the histology transition, biopsy RNA levels, and skin disease score. A: Relationship between the level of histological conversion from CD34 to $\mathrm{Pdpn}^{+}$scored as low to high and the ratio of CD34/Pdpn RNA as determined in adjacent skin biopsy specimens (significance one-way analysis of variance). B: Relationship between the modified Rodnan skin score (MRSS) measure of SSc disease and the RNA ratio of either Pdpn or CD90 to CD34 (Spearman correlation analysis). C: Heat map showing genes correlating with the Pdpn/CD34 ratio. Genes with a fdr $q<0.05$ are shown, and the subjects are ordered from right to left with increasing Pdpn/CD34 ratio. Normal subjects are marked with a black box. ${ }^{*} P<0.05$, ${ }^{* *} P<0.01$.

that CD34 expression was a hallmark of a DFSP, whereas DF and AFX were typically CD34 negative. ${ }^{61}$ In addition, DF and AFX but not DFSP are Pdpn positive. ${ }^{62-64}$ These patterns suggested that DF and AFX are composed of cells that resemble transitioned fibroblasts. Costaining for CD34/ Pdpn or CD34/CD90 showed that the spindle-like cells in DF and AFX were CD34 negative, as expected, but displayed both Pdpn and CD90. Both DFSP and neurofibroma tumor cells resemble the dermal $\mathrm{CD} 34^{+} \mathrm{SFC}$; however, neurofibromas contained some interspersed $\mathrm{CD} 90^{+}$transitioned cells. It was not within the scope of this work to determine whether these tumors were phenotypically heterogeneous or variably infiltrated (eg, in DF, AFX, or neurofibromas), with a non-transformed cancer-associated fibroblast (ie, a reactive stroma resembling the transitioned fibroblast). Nonetheless, we interpret the observations on 

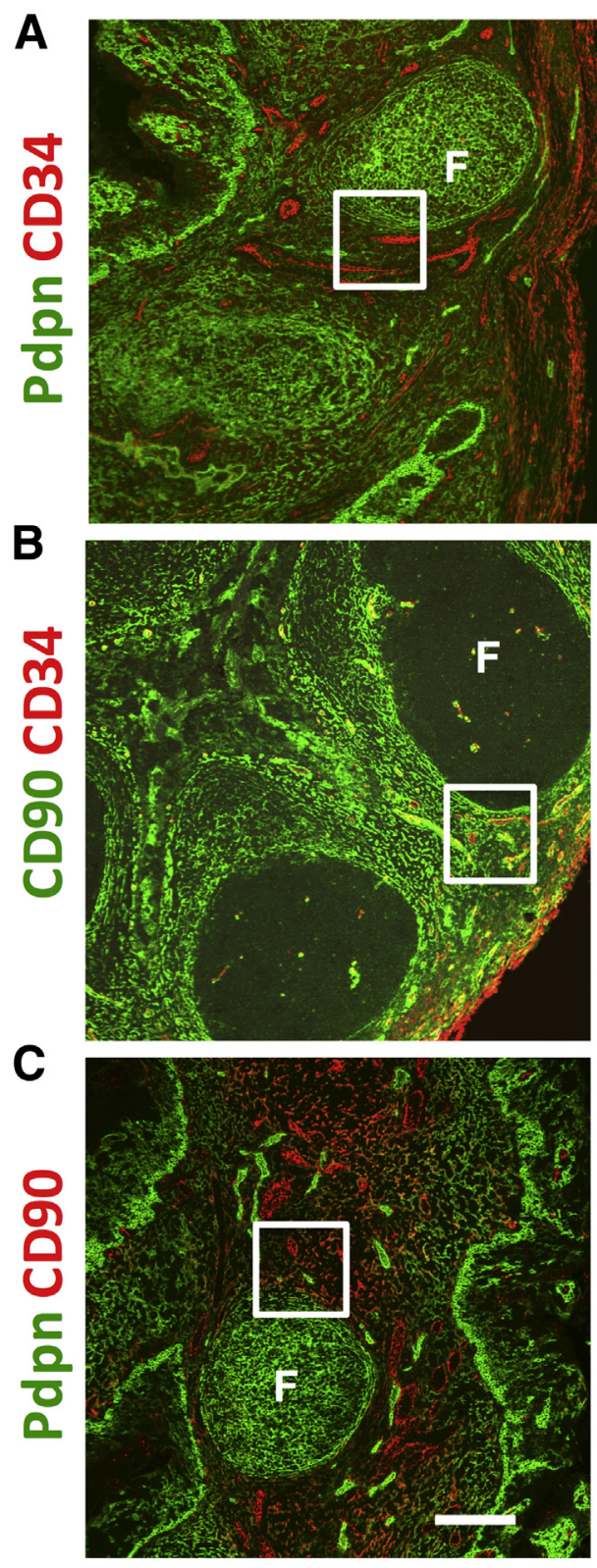
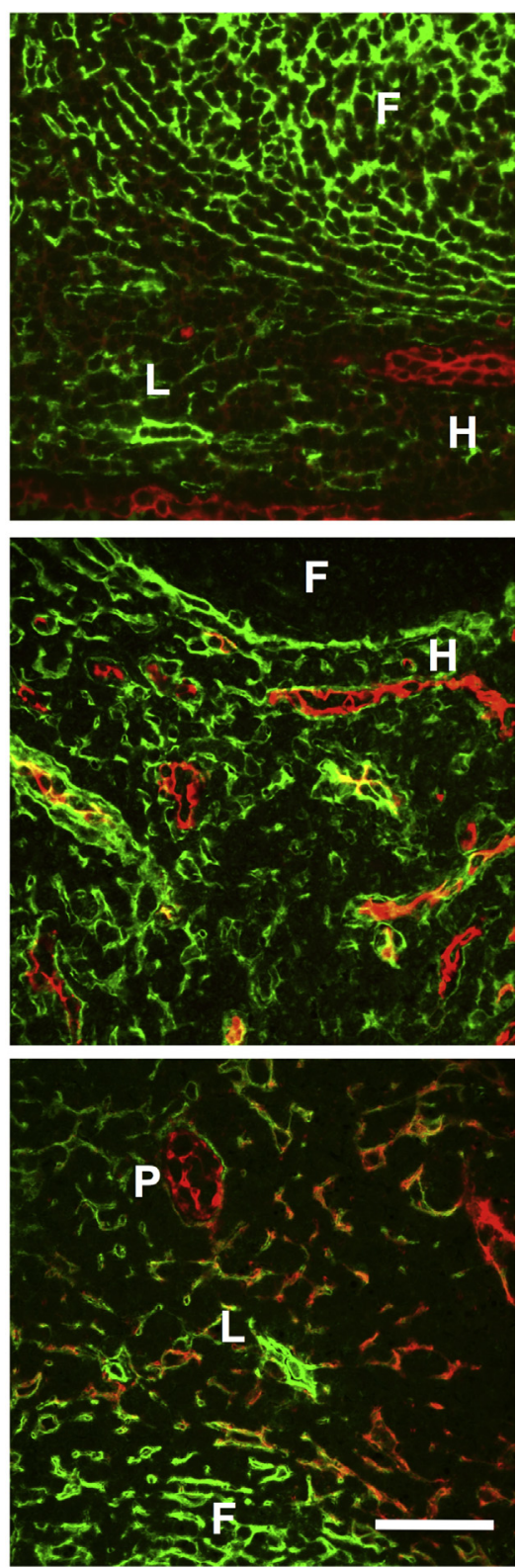

Figure 8 Fibroblastic reticular cells in the human tonsil are $\mathrm{Pdpn}^{+}, \mathrm{CD}^{+} 0^{+}$and lack CD34. Left panels: low magnification images of immunofluorescence staining of reticular networks in the human tonsil. Boxed areas are magnified in the right panels. A: The tonsil is attached to a $\mathrm{CD}_{4} 4^{+}$layer potentially resembling the $\mathrm{CD}_{3}{ }^{+} \mathrm{SFC}$ in the dermis. The CD90/CD34 pairing reveals some vascular heterogeneity (B), and $\mathrm{CD}^{+} 0^{+}$fibroblastic reticular cells. C: Follicular dendritic cell networks within the follicles display Pdpn but not CD90. In contrast, some of the fibroblastic reticular cells outside the follicles express both Pdpn and CD90 (yellow-orange cells, C). Scale bars: $200 \mu \mathrm{m}(\mathbf{A}-\mathbf{C}$, left panels); $50 \mu \mathrm{m}$ (A-C, right panels). $\mathrm{F}$, follicle; $H$, high endothelial venule; $L$, lymphatic; $P$, possible $\mathrm{CD}^{+} 0^{+}$pericyte layer. these mesenchymal and neural tumors or potentially attendant reactive stroma as consistent with the basic notion of a fibroblast conversion.

\section{Discussion}

In addition to the actual fibrosis, the extensive loss of CD34 expression in the dermal stromal cells remains one of the most dramatic histological observations in SSc. This disappearance could result from a phenotypic transition of existing dermal fibroblasts to a new state or, alternatively, cell degeneration followed by de novo replacement with fibroblasts lacking CD34 expression. Replacement cells could derive from local or immigrating progenitor cells. It is likely that in more advanced stages of the disease, there is even a general loss of cellularity. Degenerating stromal cells have been observed in SSc; however, they have not been phenotypically identified. ${ }^{28} \mathrm{We}$ propose herein that normal $\mathrm{CD}_{4}{ }^{+}$SFCs convert to $\mathrm{CD} 34^{-}$, Pdpn, or $\mathrm{CD}^{+} 0^{+}$fibroblasts, and this transition at least partially accounts for the loss of CD34 expression.

In support of this hypothesis, first, we found stromal cells in SSc skin that appeared to be caught in transition (ie, displaying Pdpn/CD90 along with CD34). Second, this transition occurs early after an incisional wound in the mouse, indicative of a quick phenotypic conversion rather than de novo immigration and replacement. At day 1 after incision, the presence of these cells precedes the appearance of myofibroblasts that occurs later in the granulation phase of wound repair. ${ }^{65}$ Third, cultured primary dermal fibroblasts convert to a $\mathrm{Pdpn}^{+}$state when exposed to the 
inflammatory triggers TNF or IL-1 $\beta$, proving that fibroblasts have the capacity at least in vitro to transition. Given the extended nature of the disease process, we cannot exclude that cellular degeneration is also occurring followed by $d e$ novo replacement with new fibroblasts having the transitioned phenotype. Recapitulation of the entire transition in vitro, including loss of CD34 and up-regulation of CD90, would help solidify this hypothesis and awaits further advances in dermal fibroblast culturing. Limitations in this study include the difficulty of using cross-sectional data to define events in a disease process progressing over several years. Interpretation is further obfuscated by variability in the extent and nature of the transition in SSc skin biopsy specimens because of either intrinsic disease heterogeneity or imprecise staging. Technically, there is the difficulty of assessing molecular phenotypes in thin sections where the cells have long thin processes and highly contorted shapes. Whole tissue imaging methods should prove useful here.

Beyond the well-documented loss of CD34 expression in $\mathrm{SSc}$, various aspects of this change have been noted previously. In the skin, normal dermal fibroblasts are $\mathrm{CD}^{-} 0^{-}$ (except for perivascular adventitial cells), yet in $\mathrm{SSc} \mathrm{CD} 90^{+}$ fibroblast-like cells were observed, including $\alpha$-SMA ${ }^{+}$ $\mathrm{CD} 90^{+}$cells, and similar changes were observed in a murine fibrosis model. ${ }^{28,52,54}$ Likewise, the reciprocal nature of CD34 and Pdpn expression forms one basis for distinguishing the types of mesenchymal skin tumors. Our observations point toward the existence of at least five phenotypes of dermal fibroblasts (ie, conventional CD34 ${ }^{+}$ SFC, CD34 ${ }^{-} \mathrm{Pdpn}^{+}, \mathrm{CD} 34^{-} \mathrm{CD} 90^{+}, \mathrm{CD} 34^{-} \mathrm{Pdpn}^{+}$ $\mathrm{CD}^{+} 0^{+}$, and $\alpha-\mathrm{SMA}^{+}$myofibroblasts with CD90 and/or Pdpn expression). Thus, this fibroblastic transition in SSc skin is consistent with prior observations in multiple settings.

The CD $34^{+}$SFC cells have been proposed to serve a sentinel function to initiate repair. ${ }^{22}$ Peduto et al ${ }^{66}$ analyzed the appearance of $\mathrm{Pdpn}^{+}$stromal cells after tissue insult in mice. In that study, $\mathrm{Pdpn}^{+}$stromal cells were derived from local cells (ie, resident fibroblasts, pericytes, or progenitors), and not from blood-borne cells or epithelial-to-mesenchymal transitioning. As the conversion occurs in systemic sclerosis, in multiple inflammatory skin diseases, and in skin injury, our data are consistent with the proposal by Peduto et al ${ }^{66}$ that this transition represents a common fibroblast response to inflammation correlating with a shift to a tissue repair program. Indeed, a generic transition model is supported by the observation that $\mathrm{CD} 34^{+}$SFC cells were lost not only in the skin, but also in the gastric lining, myocardium, and lungs of SSc patients as well as in human skin wounds, peritoneal fibrosis, and keloids. ${ }^{29-32}$ Synovial fibroblasts in the joints of rheumatoid arthritis patients also display Pdpn, suggesting that this transition accompanies inflammation. ${ }^{67,68}$

Herein, we demonstrate that fibroblasts in vitro can transition in response to inflammatory stimuli that have $\mathrm{NF}-\kappa \mathrm{B}$ activation as a common element and, likewise, as noted in an acute mouse ear model of inflammation, Toll- like receptor and interferon signaling pathways did not contribute to Pdpn induction. ${ }^{66} \mathrm{Pdpn}$ is constitutively expressed in lymphoid reticular stroma; however, when the lymph node becomes reactive or effectively inflamed, Pdpn levels increase even further. ${ }^{12,14}$ While pursuing the notion of parallels between dermal fibrotic events and the reticular networks in lymphoid tissues, we were interested in the role of alternate NF- $\kappa \mathrm{B}$ signaling and LT $\beta \mathrm{R}$ involvement. The LT $\beta R$ system is crucial for the ontogeny of reticular networks in mouse lymphoid organs and has been linked to asthmatic airway remodeling. ${ }^{66,69-71}$ Mouse fibroblastic reticular cells (FRCs) in lymph nodes make and wrap a collagen fibril, generating the conduit unit. ${ }^{11}$ Robust induction of Pdpn expression and matrix deposition in FRCs occurred in vitro with dual TNF receptor and LT $\beta R$ activation. ${ }^{57}$ In parallel with the murine FRC study, in dermal fibroblasts, LT $\beta$ R activation was not a strong inducer of Pdpn, yet combined TNF and LT $\beta$ R agonism was the most effective trigger we observed.

The triggers for decreased CD34 and increased CD90 expression remain unclear. A complication in replicating these differentiation events in vitro is that primary dermal fibroblasts transition to a CD34 low, CD90 RNA high state in cell culture. Loss of CD34 was reported on adaptation of fibroblasts into tissue culture and a similar event occurs in endothelial cells. ${ }^{22,72-75}$ Given these changes in phenotypic expression and the observation that exposure of dermal fibroblasts to serum leads to a rapid transition with many elements of a wound repair response, it is clear that dermal fibroblasts are reprogramed on culturing. ${ }^{76}$ Despite these gaps in understanding, our in vitro work and the in vivo expression patterns suggest that different programs control Pdpn and CD90.

These three heavily glycosylated surface molecules still lack precisely defined biological roles. Pdpn can partner with CD9, CD44, and galectin-8 and displays sialylated sugars that bind to the C-type lectin-2 on dendritic cells and platelets. ${ }^{43}$ More important, in the lymph node environment, Pdpn promotes actinomyosin contractility in fibroblastic reticular cells via the RhoA/C-ROCK signaling pathway. ${ }^{13,77}$ Shifts in fibroblast contractility dependent on Pdpn binding status may be especially relevant in the fibrotic setting given the attention being given to the role of matrix stiffness and mechanotransduction in fibroblasts. ${ }^{78} \mathrm{CD} 90$ has been linked to efficient wound closure. ${ }^{79}$ A more detailed comprehension of these molecular functions should improve the understanding of both physiological and pathological skin remodeling and repair.

By comparing the reticular networks found in lymphoid tissues, we have uncovered parallels in perturbed skin. FRCs are found in inflammatory diseases in organized tertiary lymphoid tissues where there is a substantial lymphocytic infiltrate (eg, the salivary gland in Sjogren syndrome and the liver in primary biliary cirrhosis). ${ }^{44}$ In contrast, the SSc skin fibroblast transition usually appears in lieu of major classic lymphocytic infiltrates. We postulate 
that the skin fibroblast transition in SSc mirrors partially the differentiation events leading to the mature lymphoid reticular networks. Further work will be needed to ascertain the extent of any functional similarity. A dendritic cellLT $\beta$ R-Pdpn axis was recently shown to be crucial for FRC specialization and maintenance of immune responses in reactive lymph nodes. ${ }^{14}$ Whether such an axis is operational in SSc or systemic lupus erythematosus skin is an interesting question.

These data suggest that changes in fibroblast status can at least partially account for the dramatic loss of CD34 ${ }^{+} \mathrm{SFCs}$ observed in SSc. SSc is commonly portrayed as a triad of autoimmunity, vasculopathy, and fibrosis, with the fibrotic component dominating the life-threatening pathology. Uncovering these fibroblast changes may provide new tools to study earlier events in SSc before the major fibrotic process. It is possible that further insight will result from linking the rapid advances in understanding the lymphoid networks as well as the stromal reaction in tumors. By defining this simple transition, it is possible that disease heterogeneity within SSc can be probed and patients more accurately staged (ie, progressive or quiescent, early or late). In addition, this transition could provide a new metric for interventional clinical studies.

\section{Acknowledgments}

We thank Salma Goummih and Christina Lisk for assistance, Romy Christmann for valuable discussion, Jessica Zeimek, Eric Stratton, Sarah McLaughlin, and Robert Simms for the SSc skin biopsy repository, and Biogen for the gift of the BS1 LT $\beta$ receptor bispecific antibody.

\section{Supplemental Data}

Supplemental material for this article can be found at http://dx.doi.org/10.1016/j.ajpath.2016.06.020.

\section{References}

1. Allanore Y, Simms R, Distler O, Trojanowska M, Pope J, Denton CP, Varga J: Systemic sclerosis. Nat Rev Dis Primers 2015, 1:15002

2. Wynn TA, Ramalingam TR: Mechanisms of fibrosis: therapeutic translation for fibrotic disease. Nat Med 2012, 18:1028-1040

3. Gilbane AJ, Denton CP, Holmes AM: Scleroderma pathogenesis: a pivotal role for fibroblasts as effector cells. Arthritis Res Ther 2013, $15: 215$

4. Lafyatis R: Transforming growth factor beta-at the centre of systemic sclerosis. Nat Rev Rheumatol 2014, 10:706-719

5. LeBleu VS, Taduri G, O'Connell J, Teng Y, Cooke VG, Woda C, Sugimoto H, Kalluri R: Origin and function of myofibroblasts in kidney fibrosis. Nat Med 2013, 19:1047-1053

6. Kramann R, Schneider RK, DiRocco DP, Machado F, Fleig S, Bondzie PA, Henderson JM, Ebert BL, Humphreys BD: Perivascular Gli1+ progenitors are key contributors to injury-induced organ fibrosis. Cell Stem Cell 2015, 16:51-66

7. Marangoni RG, Korman BD, Wei J, Wood TA, Graham LV, Whitfield ML, Scherer PE, Tourtellotte WG, Varga J: Myofibroblasts in murine cutaneous fibrosis originate from adiponectin-positive intradermal progenitors. Arthritis Rheumatol 2015, 67:1062-1073

8. Rinkevich Y, Walmsley GG, Hu MS, Maan ZN, Newman AM, Drukker M, Januszyk M, Krampitz GW, Gurtner GC, Lorenz HP, Weissman IL, Longaker MT: Skin fibrosis: identification and isolation of a dermal lineage with intrinsic fibrogenic potential. Science 2015, 348:2151

9. Roozendaal R, Mebius RE: Stromal cell-immune cell interactions. Annu Rev Immunol 2011, 29:23-43

10. Siegert S, Luther SA: Positive and negative regulation of $\mathrm{T}$ cell responses by fibroblastic reticular cells within paracortical regions of lymph nodes. Front Immunol 2012, 3:285

11. Malhotra D, Fletcher AL, Turley SJ: Stromal and hematopoietic cells in secondary lymphoid organs: partners in immunity. Immunol Rev 2013, 251:160-176

12. Yang CY, Vogt TK, Favre S, Scarpellino L, Huang HY, Tacchini-Cottier F, Luther SA: Trapping of naive lymphocytes triggers rapid growth and remodeling of the fibroblast network in reactive murine lymph nodes. Proc Natl Acad Sci U S A 2014, 111:E109-E118

13. Acton SE, Farrugia AJ, Astarita JL, Mourao-Sa D, Jenkins RP Nye E, Hooper S, van Blijswijk J, Rogers NC, Snelgrove KJ, Rosewell I, Moita LF, Stamp G, Turley SJ, Sahai E, Reis e Sousa C: Dendritic cells control fibroblastic reticular network tension and lymph node expansion. Nature 2014, 514:498-502

14. Kumar V, Dasoveanu DC, Chyou S, Tzeng TC, Rozo C, Liang Y, Stohl W, Fu YX, Ruddle NH, Lu TT: A dendritic-cell-stromal axis maintains immune responses in lymph nodes. Immunity 2015, 42: $719-730$

15. Zeng M, Haase AT, Schacker TW: Lymphoid tissue structure and HIV-1 infection: life or death for T cells. Trends Immunol 2012, 33: $306-314$

16. Grimm KE, Barry TS, Chizhevsky V, Hii A, Weiss LM, Siddiqi IN, Brynes RK, O'Malley DP: Histopathological findings in 29 lymph node biopsies with increased IgG4 plasma cells. Mod Pathol 2012, 25:480-491

17. Tataroglu C, Sarioglu S, Kargi A, Ozkal S, Aydin O: Fibrosis in Hodgkin and non-Hodgkin lymphomas. Pathol Res Pract 2007, 203: $725-730$

18. Fonseca DM, Hand TW, Han SJ, Gerner MY, Glatman Zaretsky A, Byrd AL, Harrison OJ, Ortiz AM, Quinones M, Trinchieri G, Brenchley JM, Brodsky IE, Germain RN, Randolph GJ, Belkaid Y: Microbiota-dependent sequelae of acute infection compromise tissuespecific immunity. Cell 2015, 163:354-366

19. Driskell RR, Watt FM: Understanding fibroblast heterogeneity in the skin. Trends Cell Biol 2015, 25:92-99

20. Abraham DJ, Eckes B, Rajkumar V, Krieg T: New developments in fibroblast and myofibroblast biology: implications for fibrosis and scleroderma. Curr Rheumatol Rep 2007, 9:136-143

21. Rusu MC, Mirancea N, Manoiu VS, Valcu M, Nicolescu MI, Paduraru D: Skin telocytes. Ann Anat 2012, 194:359-367

22. Diaz-Flores L, Gutierrez R, Garcia MP, Saez FJ, Diaz-Flores L Jr, Valladares F, Madrid JF: CD34+ stromal cells/fibroblasts/ fibrocytes/telocytes as a tissue reserve and a principal source of mesenchymal cells: location, morphology, function and role in pathology. Histol Histopathol 2014, 29:831-870

23. Aiba S, Tabata N, Ohtani H, Tagami H: CD34+ spindle-shaped cells selectively disappear from the skin lesion of scleroderma. Arch Dermatol 1994, 130:593-597

24. Skobieranda K, Helm KF: Decreased expression of the human progenitor cell antigen (CD34) in morphea. Am J Dermatopathol 1995 , $17: 471-475$

25. Gilmour TK, Wilkinson B, Breit SN, Kossard S: Analysis of dendritic cell populations using a revised histological staging of morphoea. $\mathrm{Br}$ J Dermatol 2000, 143:1183-1192

26. Walters R, Pulitzer M, Kamino H: Elastic fiber pattern in scleroderma/morphea. J Cutan Pathol 2009, 36:952-957 
27. de-Sa-Earp AP, do Nascimento AP, Carneiro SC, Porto LC, MonteAlto-Costa A: Dermal dendritic cell population and blood vessels are diminished in the skin of systemic sclerosis patients: relationship with fibrosis degree and disease duration. Am J Dermatopathol 2013, 35: 438-444

28. Manetti M, Guiducci S, Ruffo M, Rosa I, Faussone-Pellegrini MS, Matucci-Cerinic M, Ibba-Manneschi L: Evidence for progressive reduction and loss of telocytes in the dermal cellular network of systemic sclerosis. J Cell Mol Med 2013, 17:482-496

29. Manetti M, Rosa I, Messerini L, Guiducci S, Matucci-Cerinic M, Ibba-Manneschi L: A loss of telocytes accompanies fibrosis of multiple organs in systemic sclerosis. J Cell Mol Med 2014, 18: $253-262$

30. Aiba S, Tagami H: Inverse correlation between CD34 expression and proline-4-hydroxylase immunoreactivity on spindle cells noted in hypertrophic scars and keloids. J Cutan Pathol 1997, 24:65-69

31. Jimenez-Heffernan JA, Aguilera A, Aroeira LS, Lara-Pezzi E, Bajo MA, del Peso G, Ramirez M, Gamallo C, Sanchez-Tomero JA, Alvarez V, Lopez-Cabrera M, Selgas R: Immunohistochemical characterization of fibroblast subpopulations in normal peritoneal tissue and in peritoneal dialysis-induced fibrosis. Virchows Arch 2004, 444:247-256

32. Erdag G, Qureshi HS, Patterson JW, Wick MR: CD34-positive dendritic cells disappear from scars but are increased in pericicatricial tissue. J Cutan Pathol 2008, 35:752-756

33. Rice LM, Ziemek J, Stratton EA, McLaughlin SR, Padilla CM, Mathes AL, Christmann RB, Stifano G, Browning JL, Whitfield ML, Spiera RF, Gordon JK, Simms RW, Zhang Y, Lafyatis R: A longitudinal biomarker for the extent of skin disease in patients with diffuse cutaneous systemic sclerosis. Arthritis Rheumatol 2015, 67: 3004-3015

34. Rice LM, Padilla CM, McLaughlin SR, Mathes A, Ziemek J, Goummih S, Nakerakanti S, York M, Farina G, Whitfield ML, Spiera RF, Christmann RB, Gordon JK, Weinberg J, Simms RW, Lafyatis R: Fresolimumab treatment decreases biomarkers and improves clinical symptoms in systemic sclerosis patients. J Clin Invest $2015,125: 2795-2807$

35. Johnson WE, Li C, Rabinovic A: Adjusting batch effects in microarray expression data using empirical Bayes methods. Biostatistics 2007, 8:118-127

36. Farina GA, York MR, Di Marzio M, Collins CA, Meller S, Homey B, Rifkin IR, Marshak-Rothstein A, Radstake TR, Lafyatis R: Poly(I: C) drives type I IFN- and TGFbeta-mediated inflammation and dermal fibrosis simulating altered gene expression in systemic sclerosis. J Invest Dermatol 2010, 130:2583-2593

37. Hu X, Zimmerman MA, Bardhan K, Yang D, Waller JL, Liles GB, Lee JR, Pollock R, Lev D, Ware CF, Garber E, Bailly V, Browning JL, Liu K: Lymphotoxin beta receptor mediates caspase-dependent tumor cell apoptosis in vitro and tumor suppression in vivo despite induction of NF-kappaB activation. Carcinogenesis 2013, 34:1105-1114

38. Stifano G, Affandi AJ, Mathes AL, Rice LM, Nakerakanti S, Nazari B, Lee J, Christmann RB, Lafyatis R: Chronic Toll-like receptor 4 stimulation in skin induces inflammation, macrophage activation, transforming growth factor beta signature gene expression, and fibrosis. Arthritis Res Ther 2014, 16:R136

39. Akhmetshina A, Beer J, Zwerina K, Englbrecht M, Palumbo K, Dees C, Reich N, Zwerina J, Szucs G, Gusinde J, Nevskaya T, Distler O, Kerjaschki D, Schett G, Distler JH: Decreased lymphatic vessel counts in patients with systemic sclerosis: association with fingertip ulcers. Arthritis Rheum 2010, 62:1513-1522

40. Honda N, Jinnin M, Kajihara I, Makino T, Fukushima S, Ihn H: Impaired lymphangiogenesis due to excess vascular endothelial growth factor-D/Flt-4 signalling in the skin of patients with systemic sclerosis. Br J Dermatol 2010, 163:776-780

41. Manetti M, Milia AF, Guiducci S, Romano E, Matucci-Cerinic M, Ibba-Manneschi L: Progressive loss of lymphatic vessels in skin of patients with systemic sclerosis. J Rheumatol 2011, 38:297-301
42. Rossi A, Sozio F, Sestini P, Renzoni EA, Khan K, Denton CP, Abraham DJ, Weber E: Lymphatic and blood vessels in scleroderma skin, a morphometric analysis. Hum Pathol 2010, 41:366-374

43. Astarita JL, Acton SE, Turley SJ: Podoplanin: emerging functions in development, the immune system, and cancer. Front Immunol 2012, $3: 283$

44. Link A, Hardie DL, Favre S, Britschgi MR, Adams DH, Sixt M, Cyster JG, Buckley CD, Luther SA: Association of T-zone reticular networks and conduits with ectopic lymphoid tissues in mice and humans. Am J Pathol 2011, 178:1662-1675

45. Marsee DK, Pinkus GS, Hornick JL: Podoplanin (D2-40) is a highly effective marker of follicular dendritic cells. Appl Immunohistochem Mol Morphol 2009, 17:102-107

46. Ordonez NG: Value of podoplanin as an immunohistochemical marker in tumor diagnosis: a review and update. Appl Immunohistochem Mol Morphol 2014, 22:331-347

47. Gomaa AH, Yaar M, Bhawan J: Cutaneous immunoreactivity of D240 antibody beyond the lymphatics. Am J Dermatopathol 2007, 29: $18-21$

48. Honma M, Minami-Hori M, Takahashi H, Iizuka H: Podoplanin expression in wound and hyperproliferative psoriatic epidermis: regulation by TGF-beta and STAT-3 activating cytokines, IFNgamma, IL-6, and IL-22. J Dermatol Sci 2012, 65:134-140

49. Gerlach JC, Over P, Turner ME, Thompson RL, Foka HG, Chen WC, Peault B, Gridelli B, Schmelzer E: Perivascular mesenchymal progenitors in human fetal and adult liver. Stem Cells Dev 2012, 21: 3258-3269

50. Guillot-Delost M, Le Gouvello S, Mesel-Lemoine M, Cherai M, Baillou C, Simon A, Levy Y, Weiss L, Louafi S, Chaput N, Berrehar F, Kerbrat S, Klatzmann D, Lemoine FM: Human CD90 identifies Th17/Tc17 T cell subsets that are depleted in HIV-infected patients. J Immunol 2012, 188:981-991

51. Corselli M, Chen CW, Sun B, Yap S, Rubin JP, Peault B: The tunica adventitia of human arteries and veins as a source of mesenchymal stem cells. Stem Cells Dev 2012, 21:1299-1308

52. Juniantito $\mathrm{V}$, Izawa $\mathrm{T}$, Yuasa $\mathrm{T}$, Ichikawa $\mathrm{C}$, Tanaka $\mathrm{M}$, Kuwamura M, Yamate J: Immunophenotypical analysis of myofibroblasts and mesenchymal cells in the bleomycin-induced rat scleroderma, with particular reference to their origin. Exp Toxicol Pathol 2013, 65:567-577

53. Kissin EY, Merkel PA, Lafyatis R: Myofibroblasts and hyalinized collagen as markers of skin disease in systemic sclerosis. Arthritis Rheum 2006, 54:3655-3660

54. Rajkumar VS, Howell K, Csiszar K, Denton CP, Black CM, Abraham DJ: Shared expression of phenotypic markers in systemic sclerosis indicates a convergence of pericytes and fibroblasts to a myofibroblast lineage in fibrosis. Arthritis Res Ther 2005, 7: R1113-R1123

55. Hatakeyama K, Kaneko MK, Kato Y, Ishikawa T, Nishihira K, Tsujimoto Y, Shibata Y, Ozaki Y, Asada Y: Podoplanin expression in advanced atherosclerotic lesions of human aortas. Thromb Res 2012, 129:e70-e76

56. Zhou Y, Hagood JS, Lu B, Merryman WD, Murphy-Ullrich JE: Thy1-integrin alphav beta5 interactions inhibit lung fibroblast contraction-induced latent transforming growth factor-betal activation and myofibroblast differentiation. J Biol Chem 2010, 285: 22382-22393

57. Katakai T, Hara T, Sugai M, Gonda H, Shimizu A: Lymph node fibroblastic reticular cells construct the stromal reticulum via contact with lymphocytes. J Exp Med 2004, 200:783-795

58. Milano A, Pendergrass SA, Sargent JL, George LK, McCalmont TH, Connolly MK, Whitfield ML: Molecular subsets in the gene expression signatures of scleroderma skin. PLoS One 2008, 3:e2696

59. Christmann RB, Mathes A, Affandi AJ, Padilla C, Nazari B, Bujor AM, Stifano G, Lafyatis R: Thymic stromal lymphopoietin is up-regulated in the skin of patients with systemic sclerosis and induces profibrotic genes and intracellular signaling that overlap with 
those induced by interleukin-13 and transforming growth factor beta. Arthritis Rheum 2013, 65:1335-1346

60. Park SM, Angel CE, McIntosh JD, Brooks AE, Middleditch M, Chen CJ, Ruggiero K, Cebon J, Rod Dunbar P: Sphingosine-1phosphate lyase is expressed by CD68+ cells on the parenchymal side of marginal reticular cells in human lymph nodes. Eur J Immunol $2014,44: 2425-2436$

61. Thum C, Husain EA, Mulholland K, Hornick JL, Brenn T: Atypical fibroxanthoma with pseudoangiomatous features: a histological and immunohistochemical mimic of cutaneous angiosarcoma. Ann Diagn Pathol 2013, 17:502-507

62. Tardio JC: CD34-reactive tumors of the skin: an updated review of an ever-growing list of lesions. J Cutan Pathol 2009, 36:89-102

63. Bandarchi B, Ma L, Marginean C, Hafezi S, Zubovits J, Rasty G: D240, a novel immunohistochemical marker in differentiating dermatofibroma from dermatofibrosarcoma protuberans. Mod Pathol 2010, 23:434-438

64. Buonaccorsi JN, Plaza JA: Role of CD10, wide-spectrum keratin, p63, and podoplanin in the distinction of epithelioid and spindle cell tumors of the skin: an immunohistochemical study of 81 cases. Am J Dermatopathol 2012, 34:404-411

65. Darby I, Skalli O, Gabbiani G: Alpha-smooth muscle actin is transiently expressed by myofibroblasts during experimental wound healing. Lab Invest 1990, 63:21-29

66. Peduto L, Dulauroy S, Lochner M, Spath GF, Morales MA, Cumano A, Eberl G: Inflammation recapitulates the ontogeny of lymphoid stromal cells. J Immunol 2009, 182:5789-5799

67. Ekwall AK, Eisler T, Anderberg C, Jin C, Karlsson N, Brisslert M, Bokarewa MI: The tumour-associated glycoprotein podoplanin is expressed in fibroblast-like synoviocytes of the hyperplastic synovial lining layer in rheumatoid arthritis. Arthritis Res Ther 2011, 13:R40

68. Takakubo Y, Oki H, Naganuma Y, Saski K, Sasaki A, Tamaki Y, Suran Y, Konta T, Takagi M: Distribution of podoplanin in synovial tissues in rheumatoid arthritis patients using biologic or conventional disease-modifying anti-rheumatic drugs. Curr Rheumatol Rev 2016. doi:10.2174/1573397112666160331143607, [Epub ahead of print]

69. Lu TT, Browning JL: Role of the lymphotoxin/LIGHT system in the development and maintenance of reticular networks and vasculature in lymphoid tissues. Front Immunol 2014, 5:47
70. Remouchamps C, Boutaffala L, Ganeff C, Dejardin E: Biology and signal transduction pathways of the Lymphotoxin-alphabeta/LTbetaR system. Cytokine Growth Factor Rev 2011, 22:301-310

71. Doherty TA, Soroosh P, Khorram N, Fukuyama S, Rosenthal P, Cho JY, Norris PS, Choi H, Scheu S, Pfeffer K, Zuraw BL, Ware CF, Broide DH, Croft M: The tumor necrosis factor family member LIGHT is a target for asthmatic airway remodeling. Nat Med 2011, 17:596-603

72. Delia D, Lampugnani MG, Resnati M, Dejana E, Aiello A, Fontanella E, Soligo D, Pierotti MA, Greaves MF: CD34 expression is regulated reciprocally with adhesion molecules in vascular endothelial cells in vitro. Blood 1993, 81:1001-1008

73. Boquest AC, Shahdadfar A, Brinchmann JE, Collas P: Isolation of stromal stem cells from human adipose tissue. Methods Mol Biol 2006, 325:35-46

74. Janson DG, Saintigny G, van Adrichem A, Mahe C, El Ghalbzouri A: Different gene expression patterns in human papillary and reticular fibroblasts. J Invest Dermatol 2012, 132: $2565-2572$

75. Walmsley GG, Rinkevich Y, Hu MS, Montoro DT, Lo DD, McArdle A, Maan ZN, Morrison SD, Duscher D, Whittam AJ, Wong VW, Weissman IL, Gurtner GC, Longaker MT: Live fibroblast harvest reveals surface marker shift in vitro. Tissue Eng Part C Methods 2015, 21:314-321

76. Iyer VR, Eisen MB, Ross DT, Schuler G, Moore T, Lee JC, Trent JM, Staudt LM, Hudson J Jr, Boguski MS, Lashkari D, Shalon D, Botstein D, Brown PO: The transcriptional program in the response of human fibroblasts to serum. Science 1999, 283:83-87

77. Astarita JL, Cremasco V, Fu J, Darnell MC, Peck JR, NievesBonilla JM, Song K, Kondo Y, Woodruff MC, Gogineni A, Onder L, Ludewig B, Weimer RM, Carroll MC, Mooney DJ, Xia L, Turley SJ: The CLEC-2-podoplanin axis controls the contractility of fibroblastic reticular cells and lymph node microarchitecture. Nat Immunol 2015, $16: 75-84$

78. Ho YY, Lagares D, Tager AM, Kapoor M: Fibrosis: a lethal component of systemic sclerosis. Nat Rev Rheumatol 2014, 10: 390-402

79. Lee MJ, Shin JO, Jung HS: Thy-1 knockdown retards wound repair in mouse skin. J Dermatol Sci 2013, 69:95-104 